\title{
Oral Delivery of Biologics in Inflammatory Bowel Disease Treatment
}

\author{
Wunan Zhang, Cecilia Bohns Michalowski and Ana Beloqui* \\ Advanced Drug Delivery and Biomaterials, Louvain Drug Research Institute, Université Catholique de Louvain, Brussels, \\ Belgium
}

Inflammatory bowel disease (IBD) has been posed as a great worldwide health threat. Having an onset during early adulthood, IBD is a chronic inflammatory disease characterized by remission and relapse. Due to its enigmatic etiology, no cure has been developed at the moment. Conventionally, steroids, 5-aminosalicylic acid, and immunosuppressants have been applied clinically to relieve patients' syndrome which, unfavorably, causes severe adverse drug reactions including diarrhea, anemia, and glaucoma. Insufficient therapeutic effects also loom, and surgical resection is mandatory

OPEN ACCESS

Edited by:

Didier Merlin,

Georgia State University,

United States

Reviewed by:

Pradeep Dudeja,

University of Illinois at Chicago,

United States

Guillermo Bastida,

La Fe Hospital, Spain

${ }^{*}$ Correspondence:

Ana Beloqui

ana.beloqui@uclouvain.be

Specialty section:

This article was submitted to

Nanobiotechnology,

a section of the journal

Frontiers in Bioengineering and

Biotechnology

Received: 02 March 2021

Accepted: 19 April 2021

Published: 03 June 2021

Citation:

Zhang W, Michalowski $C B$ and

Beloqui A (2021) Oral Delivery

of Biologics in Inflammatory Bowel

Disease Treatment.

Front. Bioeng. Biotechnol. 9:675194.

doi: 10.3389/fbioe.2021.675194 in half of the patients within 10 years after diagnosis. Biologics demonstrated unique and differentiative therapeutic mechanism which can alleviate the inflammation more effectively. However, their application in IBD has been hindered considering their stability and toxicity. Scientists have brought up with the concept of nanomedicine to achieve the targeted drug delivery of biologics for IBD. Here, we provide an overview of biologics for IBD treatment and we review existing formulation strategies for different biological categories including antibodies, gene therapy, and peptides. This review highlights the current trends in oral delivery of biologics with an emphasis on the important role of nanomedicine in the development of reliable methods for biologic delivery in IBD treatment.

Keywords: inflammatory bowel disease, biologics, oral drug delivery, antibody, therapeutic peptide, oligonucleotides, gene therapy

\section{INTRODUCTION}

Inflammatory bowel disease (IBD) is defined as a systemic, autoimmune, relapsing-remitting chronic disease of the gastrointestinal system whose peak incidence commonly comes off in twenties to thirties (Khor et al., 2011; Zhang and Li, 2014; Lichtenstein et al., 2018). Ulcerative colitis (UC) and Crohn disease (CD) are two major forms of IBD (Baumgart and Carding, 2007; Nikolaus and Schreiber, 2007; Strober et al., 2007). Shared with overlapped syndromes of abdominal pain, fever, bowel obstruction, and diarrhea with the passage of blood or mucus, or both, these two forms can be distinguished by diverse pathological features (Nikolaus and Schreiber, 2007). Starting from the rectum, inflammation of UC continuously spreads through the whole colon with superficial mucosal layer affected, while $\mathrm{CD}$ is characterized by intermittent inflammation areas alongside the entire gastrointestinal system and inflammatory lesions could invade all layers of the gut wall (Thompson and Lees, 2010). 
Posed as a global health threat, the incidence rates of CD and UC varied worldwide between 0.1 and 16 per 100,000 inhabitants and $0.5-24.5$ per 100,000 inhabitants, respectively (Kanaan et al., 2012). North America and Europe contracted with the highest popularity of the disease. There are approximately 1.5 million IBD patients in the United States and 2.2 million in Europe (Molodecky et al., 2012). A concerning increasing trend of incidence in Asia has also been reported in recent years (Prideaux et al., 2012). Westernization of lifestyle, diet, genetic susceptibility, microbiome, and abuse of antibiotics have been identified as risk factors for IBD (Ananthakrishnan et al., 2018); however, the precise pathogenesis remains enigmatic, causing an indomitable hindrance of IBD treatment (Shanahan, 2001). Until now, IBD is incurable and abides with compromised therapeutic strategies aiming at alleviation of the syndromes. Current IBD therapy focuses on induction and maintenance of remission in company with endoscopic healing and reduction of hospitalization and surgery (Peyrin-Biroulet et al., 2014).

Therapeutic approaches for IBD treatment should be individualized based on the disease severity, complications, location, and prognosis. According to the guidelines by the American Gastroenterological Association (AGA), European Crohn's and Colitis Organization (ECCO) together with the European Federation of Crohn's and Ulcerative Colitis Associations (EFCCA), British Society of Gastroenterology, and National Institute for Health and Care Excellence (NICE), 5-aminosalicylic acid (5-ASA) compounds, comprehending sulfasalazine, mesalamine, and diazo-bonded 5-ASA, is the first-line and standard treatment recommended to treat patients with extensive mild to moderate UC. Depending on the severity of the disease and the localization, oral and rectal administration can be combined, and different dosages and lower or higher doses of the drugs are suggested. Corticosteroids are only recommended in the case of UC patients refractory to 5-ASA, because of their significant adverse effects (Leone et al., 2016; Ko et al., 2019; Lamb et al., 2019; National Institute for Health and Care Excellence, 2019b). Fecal microbiota transplantation could be performed only in the context of clinical trial (Singh et al., 2015). By the moment, there are no recommendations in guidelines for the use of curcumin or probiotics. Regarding the maintenance of the remission, the use of 5-ASA medications seems to be effective, and in long-term use, it might reduce the risk of bowel cancer. The use of azathioprine should be considered when steroids are needed to keep the patient in remission. Those who fail to respond to azathioprine (Leone et al., 2016; Lamb et al., 2019) should be treated with antitumor necrosis factor- $\alpha$ (TNF- $\alpha$ ) or tacrolimus; however, the evidence is not so convincing for tacrolimus (Leone et al., 2016). In the case of acute severe UC, the patient should be hospitalized and the first-line treatment is corticosteroids and those who fail to respond should be treated with infliximab or ciclosporin (Lamb et al., 2019).

Regarding $\mathrm{CD}$, the treatment does not follow the same protocol, ECCO, British Society of Gastroenterology, American College of Gastroenterology, and NICE guidelines recommend corticosteroids as first-line treatment, such as budesonide, for mild-to-moderate disease and systemic corticosteroids, such as prednisolone or methylprednisolone, for moderateto-severe disease treatment (Lichtenstein et al., 2018; Lamb et al., 2019; National Institute for Health and Care Excellence, 2019a; Torres et al., 2020). However, because of the adverse effects and lack of efficacy on the maintenance of remission, corticosteroid treatment is not recommended for long-term remission and after the induction of remission, it can be substituted by thiopurine or methotrexate (Lichtenstein et al., 2018). Monoclonal antibodies are only recommended if patients do not respond to conventional therapy (Lichtenstein et al., 2018; Lamb et al., 2019; National Institute for Health and Care Excellence, 2019a; Torres et al., 2020).

\section{CURRENT BIOLOGICS IN CLINICAL IBD TREATMENT}

The chronicity of the disease and failure of standard treatments trigger a huge amount of scientific inquiry for new treatments allowing maintained remission in patients. Nowadays, biological treatments such as antibodies represent an alternative in IBD treatment and have evidenced reduction in hospitalizations (Shanahan, 2001; Mao et al., 2017) and improvement of life quality, mucosal healing (Peyrin-Biroulet et al., 2014; Cholapranee et al., 2017), and clinical remission. However, biological treatments are still the last option after 5-ASA, corticosteroids, and immunosuppressants. As for antibodies, all of them have the potential of immunogenicity, affecting their efficacy and safety (Danese et al., 2015). Therefore, TNF- $\alpha$ blockers, that have already been widely used in IBD treatment, are administered in combination with immunomodulators such as thiopurines and methotrexate, as it may reduce the formation of antidrug antibody (Molodecky et al., 2012).

In this review, we categorized both large biomolecules such as antibodies and oligonucleotides, and small molecular peptides as biological treatment. For all of those reagents, they target mediators of inflammation, including TNF- $\alpha$, selective antiadhesion molecules such as $\alpha 4$ integrins, IL-12/IL-23, and interferon (IFN)- $\gamma$, Janus kinases (JAK), and sphingosine-1phosphatase (S1P) receptor inhibitors (Rutgeerts et al., 2009; Hanauer, 2010; Cohen and Dalal, 2015; Danese et al., 2015; Katsanos et al., 2019). In this part, we summarize the biologics in clinical application for IBD treatment (Table 1).

\section{TNF- $\alpha$ Inhibitors}

Four antibodies have been approved as anti-TNF- $\alpha$ treatment: infliximab, adalimumab, certolizumab pegol, and golimumab. Infliximab is administered intravenously at a dose of $5 \mathrm{mg} / \mathrm{kg}$ in the weeks 0,2 , and 6 for induction of remission and after every 8 weeks, while adalimumab, certolizumab pegol, and golimumab are administered subcutaneously (SC). Adalimumab is administered at a dose of $160 \mathrm{mg}$ in the week 0 , followed by $80 \mathrm{mg}$ after 2 weeks and then $40 \mathrm{mg}$ every 2 weeks. Certolizumab pegol is administered at a dose of $400 \mathrm{mg}$ in the 0,2 , and 4 weeks followed by the same dose every 4 weeks (Bernstein, 2015; National Institute for Health and Care Excellence, 2019b) and finally, golimumab is administered at a dose of $200 \mathrm{mg}$ in week 
TABLE 1 | Biologics in the clinics for IBD treatment.

\begin{tabular}{|c|c|c|}
\hline \multicolumn{3}{|c|}{ Biologics for IBD in the clinics } \\
\hline Name & Mechanism & $\begin{array}{l}\text { Delivery } \\
\text { approach }\end{array}$ \\
\hline $\begin{array}{l}\text { Infliximab (Bernstein, 2015; } \\
\text { National Institute for Health and } \\
\text { Care Excellence, 2019b) }\end{array}$ & \multirow[t]{4}{*}{ Anti TNF- $\alpha$ antibodies } & Intravenous \\
\hline $\begin{array}{l}\text { Adalimumab (Bernstein, 2015; } \\
\text { National Institute for Health and } \\
\text { Care Excellence, 2019b) }\end{array}$ & & \multirow[t]{3}{*}{ Subcutaneou } \\
\hline $\begin{array}{l}\text { Certolizumab pegol (Bernstein, } \\
\text { 2015; National Institute for } \\
\text { Health and Care Excellence, } \\
\text { 2019b) }\end{array}$ & & \\
\hline $\begin{array}{l}\text { Golimumab (Probert et al., } \\
\text { 2018) }\end{array}$ & & \\
\hline $\begin{array}{l}\text { Natalizumab (National Institute } \\
\text { for Health and Care Excellence, } \\
\text { 2019a) }\end{array}$ & Anti $\alpha_{4}$ integrin antibody & Intravenous \\
\hline Vedolizumab (Bernstein, 2015) & Anti $\alpha_{4} \beta_{7}$ integrin antibody & Intravenous \\
\hline $\begin{array}{l}\text { Ustekinumab (Amiot and } \\
\text { Peyrin-Biroulet, 2015) }\end{array}$ & Anti IL antibody & Intravenous \\
\hline Tofacitinib (Agrawal et al., 2020) & $\begin{array}{l}\text { Non-selective Janus kinase } \\
\text { (JAK) inhibitor }\end{array}$ & Oral \\
\hline
\end{tabular}

0 followed by a dose of $100 \mathrm{mg}$ after 2 weeks and after week 6 at a dose of 50 or $100 \mathrm{mg}$, depending on body weight, every 4 weeks (Probert et al., 2018).

\section{Antiadhesion Molecules}

Antiadhesion therapy is based on the capacity of the molecules to block the integrins on the surface of $\mathrm{T}$ cells, preventing cellular homing to the gut (Zundler et al., 2017). Integrins mainly involved in lymphocyte migration are $\alpha_{2} \beta_{2}$ and $\alpha_{4}\left(\alpha_{4} \beta_{1}\right.$ and $\alpha_{4} \beta_{7}$ ), and the inflamed gut in IBD patients presents a higher adhesiveness for $\alpha_{4}$ integrins. Two antibodies targeting $\alpha_{4}$ integrins are actually on the market: Natalizumab is an antibody against human $\alpha_{4}$ integrin while vedolizumab is an antibody that is specific for $\alpha_{4} \beta_{7}$ heterodimer (Ghosh and Panaccione, 2010; Danese et al., 2015). Another antibody, etrolizumab is a gut-selective monoclonal antibody against the $\beta_{7}$ subunit of the heterodimeric integrins $\alpha_{4} \beta_{7}$ and $\alpha_{E} \beta_{7}$ and has just completed a phase III study. Most of the guidelines recommend the use of vedolizumab for the maintenance of remission in patients with moderate-to-severe CD given in monotherapy in a dose of 300 mg IV every 8 weeks (Torres et al., 2019).

Alicaforsen is a human antisense oligonucleotide inhibitor of the intercellular adhesion molecule ICAM-1, consequentially blocking leukocyte recruitment (Katsanos et al., 2019). Currently, a phase III study for the treatment of pouchitis (inflammation of the ileal pouch) has been completed in which the drug was administered as an enema in a dose of $240 \mathrm{mg}$ daily for 6 weeks.

\section{Anti-interleukin Drugs}

Ustekinumab is an antibody targeting the p40 subunit, a common component for interleukin (IL)-12 and IL-23. Clinical evidence supported its efficacy in remission maintenance in patients with moderate-to-severe $\mathrm{CD}$ who failed to respond to standard or anti TNF- $\alpha$ treatment (Amiot and Peyrin-Biroulet, 2015). The antibody is primarily administered as a single IV infusing over $1 \mathrm{~h}$ depending on patients' body weight and then injected subcutaneously $90 \mathrm{mg}$ SC every 8 weeks. Two other anti-IL-23 antibodies, risankizumab and brazikumab, are in phase II clinical trials (Katsanos et al., 2019).

\section{Janus Kinase Inhibitors}

Tofacitinib, a non-selective Janus kinase (JAK) inhibitor, was approved in Europe in 2018 for UC treatment. Although this small molecular drug can be orally administered, it presents some considerable adverse effects such as thromboembolism, infections, and hyperlipidemia (Agrawal et al., 2020). Filgotinib and upadacitinib are JAK1 inhibitors and have just finished the phase II studies, and phase III randomized clinical trials are currently underway (Katsanos et al., 2019). As tofacitinib, both are orally administered.

\section{Sphingosine 1 Phosphate Receptor Modulator}

Etrasimod and ozanimod are sphingosine 1 phosphate (S1P) receptor modulators. $\mathrm{S} 1 \mathrm{P}$ is responsible for the regulation of lymphocyte trafficking, and S1P modulators can interact with the receptor to induce its internalization and inhibit the egress of the lymphocytes from the lymphoid tissue, reducing their accumulation in the inflamed intestinal tissue. Etrasimod has finished the phase II study; it was administered $2 \mathrm{mg}$ orally once daily, and the results showed improvement in Mayo clinical scores (MSC). A phase III study is underway (Sandborn et al., 2020). Ozanimod is also an S1P modulator and was administered orally in a dose of $1 \mathrm{mg} /$ day presenting slightly better results than the placebo group; however, the study was considered not large or long enough to verify efficacy and safety (Sandborn et al., 2016).

\section{ORAL IBD TREATMENT STRATEGIES}

Different pathophysiological signaling pathways have been addressed through new biological treatments. However, limitations of their route of administration bring about slacked clinical compliance, adverse effects, refractory response to treatment, finite efficacy, and high price of treatments, and there is an urgent need to develop new delivery systems. Most of the strategies for conventional IBD treatments are preferred to have a local effect as some of the main pathological manifestations are limited to the intestinal tissue. An oral administration that could directly deliver the drug to the pathogenic site would be desirable (Kesisoglou and Zimmermann, 2005; Dahan et al., 2010), as non-target therapies promote systemic absorption leading to adverse effects and lower efficacy (Rutgeerts et al., 2009; Lee S. H. et al., 2020). On the other hand, oral administration for biologics is challenging since biologics are highly susceptible to the gastrointestinal environment and most of the molecules present limited transport across the intestinal epithelium due to their large size (Anselmo et al., 2019). The main oral strategies for a better performance of biological drugs are chemical modification 
or formulation-based technologies (Dahan et al., 2010). They are focused on the pathophysiological modifications of the inflamed intestinal tissue such as the production of reactive oxygen species, modification of the $\mathrm{pH}$, mucus production, overexpression of enzymes and receptors, and even changes in the gut microbiota.

Some of the recent strategies (Figure 1) used for oral delivery that could be applied in the treatment of IBD are as follows:

\section{Polymer-Based Micro/Nanoparticulate Systems}

Small nanoparticles $(\mathrm{NP})(<200 \mathrm{~nm})$ can reach the intestinal wall with enhanced permeability (Yang and Merlin, 2019). Some pathophysiological characteristics of the inflamed intestinal tissue favor NP accumulation: the increased mucus release seems to improve NP residence on the inflamed site, the destruction of the intestinal barrier increases the NP permeability, and NPs can be taken up by immune cells via endocytosis (Beloqui et al., 2016; Li et al., 2020). Other advantages of NPs are that they enable the controlled release profile reducing the adverse effects and dosing frequency. Some of the main important characteristics linked to the development of NPs to target the IBD site are described below.

\section{Size}

Lamprecht et al. (2001) showed that particles with $100 \mathrm{~nm}$ presented better accumulation than 1 or $10 \mu \mathrm{m}$ particles in the inflamed site in a TNBS model, other studies obtained similar results such as polystyrene particles in a DSS model where particles of 40 and $100 \mathrm{~nm}$ had higher accumulation than 0.5 and $1 \mu \mathrm{m}$ particles (Vong et al., 2012).

\section{Surface Characteristics}

The mucus in IBD is characterized by the presence of negatively charged colonic mucins. Thus, cationic NPs can enhance surface binding via electrostatic interactions and prolong the drug residence time. At the same time, positively charged proteins such as transferrin and eosinophil cationic proteins can also be found in the mucus in inflamed regions which benefits negatively charged particles. As the electrostatic interactions of NPs negatively charged in the mucus are weaker, they can better penetrate the mucus as cationic NPs can be immobilized due to a stronger interaction (Li et al., 2020).

Coating NPs with poly(ethylene glycol) (PEG) can be described as PEGylation and is a common strategy to improve the stability of the NPs in the gastrointestinal tract, likewise improving their absorption. The hydrophilic surface of the NPs created by the presence of the PEG minimizes the mucoadhesion, improving their diffusion (Hua et al., 2015; Suk et al., 2016).

\section{Targeting Systems}

The presence of a higher concentration of reactive oxygen species on the site of intestinal inflammation as well as inflammatory markers can provide targets for more specific delivery of drugs through surface-modified NPs. Redox-sensitive NPs containing budesonide showed a better accumulation in inflamed tissues and an improved efficacy compared with the drug suspension in a DSS-induced colitis model in male BALB/c mice (Sun et al., 2018). In another study, the accumulation of $40 \mathrm{~nm}$ coreshell-type micelles $\left(\mathrm{RPN}^{\circ}\right)$ formed by a new redox polymer in the inflamed area were evaluated in a DSS-induced colitis model in ICR mice, showing a greater accumulation in the inflamed area without absorption to the bloodstream (Vong et al., 2012). Different inflammatory markers can also be used as a target such as CD98, CD44, and folate and mannose receptor, all overexpressed on the surface of colon epithelial cells and macrophages and peptide transporter-1 (Pept1) to target macrophages (Yang et al., 2020). Recently, hyaluronic acid has been used to selectively target CD44 (Misra et al., 2015; Lee Y. et al., 2020) while lysine-proline-valine (KPV), a C-terminal peptide fragment of a $\alpha$-melanocyte-stimulating hormone, can target Pept1 (Wu et al., 2019).

\section{pH-dependent systems}

Nanoparticles could be coated with a $\mathrm{pH}$-responsive polymer allowing the drug to release in specific $\mathrm{pH}$. Methacrylic acid copolymers (Eudragit ${ }^{\circledR}$ ) for the colonic delivery of NPs are already well described for non-biological treatments (Beloqui et al., 2014; Naeem et al., 2018; Zhou and Qian, 2018).

\section{Enzyme-responsive systems}

The microflora present in the colon releases some enzymes to degrade natural polysaccharides, and these polymers can be used accordingly as an alternative coating for NPs to target the colon. Some polymers have already been described in the literature such as guar gum (Kumar et al., 2017), chitosan (Chen et al., 2020), pectin, sodium alginate, and dextran. These polymers are hydrophilic and have the advantage of limited swelling capacity in acidic pH (Rajpurohit et al., 2010).

\section{Lipid-Based Nanosystems}

Liposomes have the advantage of the possibility of encapsulating both lipophilic and hydrophilic drugs, and they can also have their surfaces modified to target the inflamed colon. Solid lipid NPs are more stable systems and better protect the drug providing a more extended release because of the slow degradation of the matrix (Singh et al., 2015; Lee S. H. et al., 2020). Another lipid-based nanosystem is the self-microemulsifying delivery system that is mostly used to encapsulate lipophilic drugs. A surface modification with folate was already performed in this kind of system to improve the solubility of curcumin and also its delivery to the colon (Zhang et al., 2012).

\section{Natural Nanomedicine}

Recently, NPs synthesized with natural products have been developed to overcome problematic issues of polymeric NPs such as toxicity and scale up for their synthesis (Yang et al., 2020). Some of the examples are ginger-derived nanolipids developed for short-interfering RNA (siRNA) delivery against CD98 (Zhang et al., 2017) and Lycium barbarum-lipid-based NPs which present excellent anti-inflammatory properties ( $\mathrm{Zu}$ et al., 2020). Other natural nanosized structures of interest are the exosome like, which can present biological effects likewise transport property. As an example, grape exosome-like NPs could induce protection against colitis in a DSS-induced mice model via the proliferation of intestinal stem cells (Ju et al., 2013). 


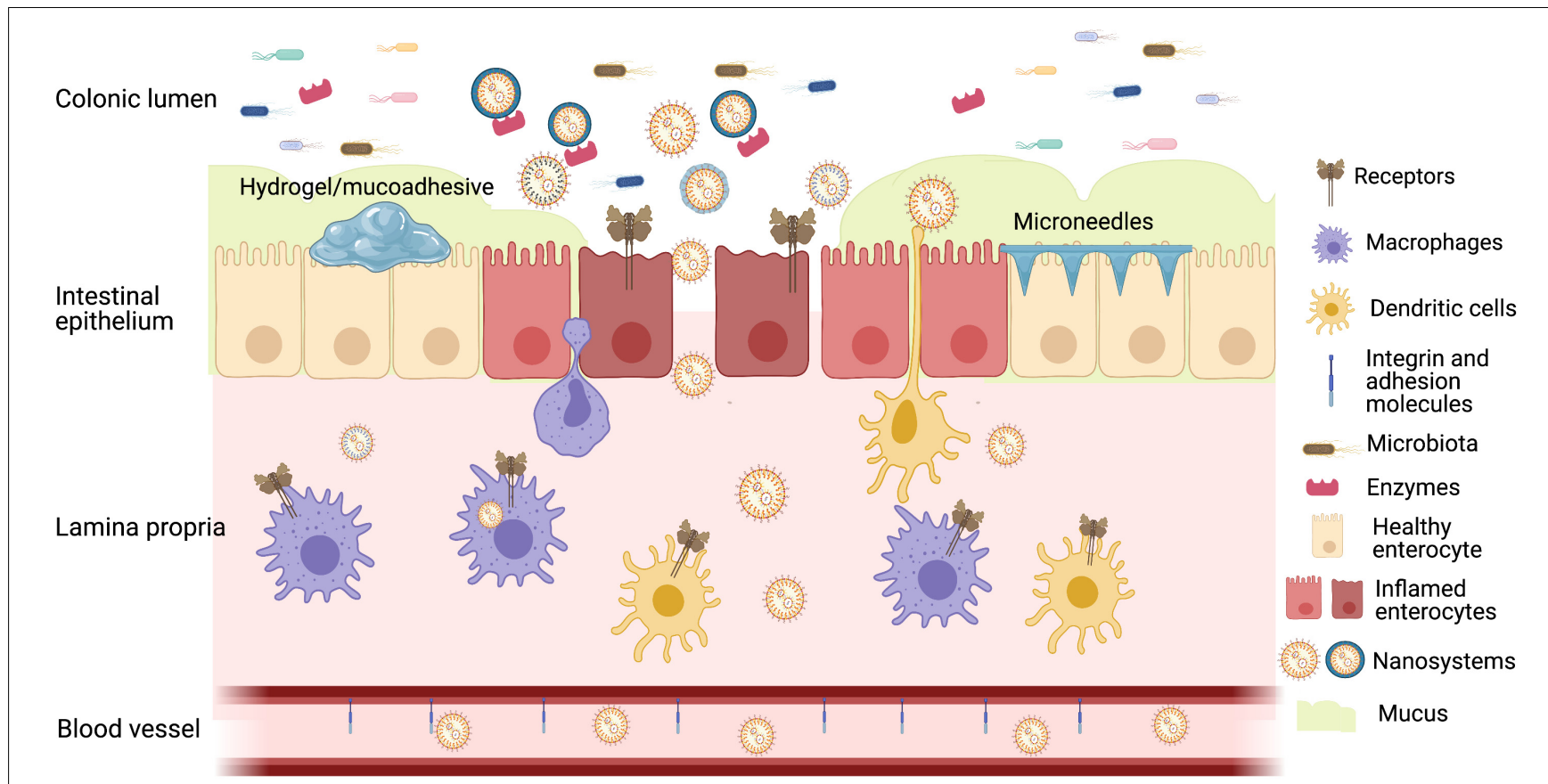

FIGURE 1 | Representative image of oral strategies for colon drug delivery based on inflamed mucosa presenting decreased diversity in microbiota, overexpression of receptors, enzymes, and redox substances, increased permeability, activation of immune system, and decreased mucus barrier. Created with BioRender.com.

\section{Hydrogel-Based Systems}

Nanogels are a platform that could protect the drug or nanosystem from the acidic $\mathrm{pH}$ of the upper part of the GIT releasing the content once it arrives in the intestinal tract. Laroui et al. (2010) developed an alginate-chitosan hydrogel for the delivery of a tripeptide (KPV) and also CD98 siRNA/PEI-loaded NPs (Laroui et al., 2014), while Knipe et al. (2016) developed an enzyme and $\mathrm{pH}$-responsive microencapsulated nanogel for the delivery of siRNA-targeting TNF- $\alpha$.

\section{Mucoadhesive Patches}

They consist of an enteric capsule containing layers of a mucoadhesive film containing the drug in the middle layer and an external backing layer that protects the drug from degradation by the luminal proteolytic enzymes (Eiamtrakarn et al., 2002). This patches allows the drug to diffuse in a unidirectional way, by creating a higher concentration matrix (Anselmo et al., 2019).

\section{Genetic Engineering Approaches}

Genetic engineering approaches include the use of genetically modified bacteria (probiotics) that produce and secrete biotherapeutics in the disease site under the stimuli of a biomarker such as nitric oxide in $\mathrm{CD}$. These bacteria can also accumulate at the sites containing higher concentrations of the biomarker (McKay et al., 2018).

\section{Traditional Pharmaceutical Forms}

The use of reversible permeation enhancers is one of the strategies used nowadays to improve the absorption of macromolecules, and one of the substances that are widely used is chitosan.
Another strategy is the use of natural mucoadhesive polymers such as gelatin, pectin, chitosan, and others (Mantaj and Vllasaliu, 2020). Modified release systems deliver the drug to the site of action in a controlled manner, and some formulations are already in the market as conventional treatments (Doherty and Peppercorn, 2009; Kornbluth, 2015). One of the new technology developed is the "microneedle pills" that were developed to only perform a physical change with no need to modify the drug or the requirement of a specific formulation (Schoellhammer et al., 2016). The microneedles attach to the intestinal epithelium and break it, facilitating the physical absorption of the drug (Anselmo et al., 2019). Traverso et al. (2015) did an in vivo proof of concept in swine using as a model macromolecule insulin, and the systemic delivery of the drug was analyzed after serial injections in different sites: gastric, duodenal, and colonic mucosa. The study proved that the system could improve the bioavailability of the macromolecule in all of the cases and that the system could be administered and excreted from the GI tract safely (Traverso et al., 2015).

\section{Intestinal Microbiota}

Dysbiosis, or the alteration of gut microbiota, is one of the factors present in IBD. Healthy individuals present a significant different microbiota compared with individuals with IBD, who present a decrease in commensal bacteria diversity, abnormal composition, and altered spatial distribution (Khan et al., 2019; Guo et al., 2020). Studies showed that some metal NPs that could regulate the intestinal microbiota reduced IBD symptoms (Yang et al., 2020). Nowadays, synbiotics, a combination of pre- and 
probiotics are being tested for IBD treatment; however, only few studies are available (Khan et al., 2019).

\section{ORAL DELIVERY OF BIOLOGICS IN IBD TREATMENT}

\section{Monoclonal Antibodies}

The dysfunction of different cytokines in IBD does not only drive intestinal inflammation but also is associated with complications of IBD such as intestinal stenosis, fistula formation, and colitisassociated neoplasias (Neurath, 2014). Respectively, CD is usually outlined with an elevated level of IL-12, IL-23, interferon (IFN)- $\gamma$, and IL-17 secreted by T helper-type (Th) 1 and Th17, whereas UC is usually designated with escalated Th2 production including IL-13, IL-5, and IL-9 (De Souza and Fiocchi, 2016). Antibodies blocking proinflammatory cytokines such as TNF, IL-12/IL-23p40, IFN- $\gamma$, IL-6R, IL-11, IL-13, and IL-17A have been studied as potential modalities for IBD (Neurath, 2014; De Souza and Fiocchi, 2016; Guan and Zhang, 2017). This concept was not validated until clinical approval of infliximab in 1997 (Markham and Lamb, 2000).

TNF- $\alpha$ is initiatively secreted as a $26-\mathrm{kD}$ transmembrane protein (tmTNF), subsequently cleaved off by TNF- $\alpha$-converting enzyme (TACE) to generate soluble TNF. Soluble TNF- $\alpha$ further reacts with different TNF- $\alpha$ receptors (TFR) to initiate a series of inflammatory reactions (Levin et al., 2016). Anti-TNF- $\alpha$ antibodies block the interaction between TNF- $\alpha$ molecules and TNFR1 and TNFR2 as well as soluble TNF- $\alpha$ receptors (sTNFR), neutralize TNF- $\alpha$-mediated proinflammatory cell signaling, and inhibit the expression of inflammatory genes (Nielsen and Ainsworth, 2013). However, etanercept, a TNF receptor fusion protein to nullify sTNF- $\alpha$ and inapt to bind tmTNF- $\alpha$ is not effective in IBD patients (Sandborn et al., 2001), implying more convoluted mechanisms are involved in anti-TNF- $\alpha$ antibody therapy for IBD treatment. Recent publications substantiated that infliximab and other anti-TNF- $\alpha$ antibodies reduced $\mathrm{T}$ cell proliferation capability through the binding between the drug and tmTNF- $\alpha$ on activated T cells (Vos et al., 2012). Once bound, a distinct macrophage subset (CD14 + HLADR + CD206 +) was induced by the interaction between Fc region and antigenpresenting cells with specific immunosuppressive capacities. CD206 + then inhibited T cell proliferation (Vos et al., 2011). These CD206 + macrophages also had wound-healing properties and were able to cause mucosal healing in an in vitro model (Vos et al., 2012).

The complex mechanisms behind antibody therapy accelerated the establishment of new types of antibodies for IBD. After the approval of infliximab, six sequential monoclonal antibodies were approved as previously described. These monoclonal antibodies rendered crucial alternatives, especially to patients who failed to respond to the conventional drug. However, $10-40 \%$ of the patients do not respond to anti-TNF- $\alpha$ antibody treatment during precursory induction therapy, and $24-46 \%$ of patients have a secondary loss of response in the first year of treatment (Ben-Horin and Chowers, 2011). This partially contributes to the antibody's immunogenicity, which can lower plasma drug concentration by inducing antidrug antibody (Kennedy et al., 2019). A colon-targeting delivery via the oral route is competent to exempt patients from long-term injection pain. With lowered systemic drug concentration, it is capable of downsizing the output of antidrug antibodies and reduce or even counterpart ADRs of biologics, implicitly providing a safer platform with improved therapeutic efficacy. However, until now, biologics can only be administered either subcutaneously or intravenously. At the moment, multiple oral approaches are under development for monoclonal antibody delivery for IBD treatment.

Most antibodies are vulnerable, confronting stomach acid and trypsin, chymotrypsin, or other enzymes abundant in the intestine and degrade before arriving at the inflammatory colon area (Yun et al., 2013). Antibody modifications can enhance their survival in the gastrointestinal tract. AVX-470 was generated by purifying immunoglobulin (Ig) from the colostrum of cows immunized with recombinant human TNF (Bhol et al., 2013). This chimeric antibody can efficiently increase proteolysis resistance and ride out the gastrointestinal tract owing to the virtue of immunoglobulins from bovine colostrum (Roos et al., 1995). In one early animal study involving acute dextran sulfate sodium (DSS)-induced colitis mice model, chronic DSS-induced mice model, and 2,4,6-trinitrobenzene sulfonic acid (TNBS)induced colitis mice model, mice orally delivered with AVX-470 (mAVX-470) reduced colitis severity observed by endoscopy. Particularly, in chronic DSS-induced colitis models, mice treated with mAVX-470 demonstrated recovery of both body weight loss and colon length after DSS treatment, implying amelioration of colonic inflammation (Bhol et al., 2013). Later in 2013, AVX470 was under first phase clinical trial to assess its safety, pharmacokinetics, immunogenicity, and preliminary efficacy in patients with active UC. Across all AVX-470 doses, 25.9\% of patients achieved clinical response compared with $11.1 \%$ on placebo, with the greatest improvements in the 3.5-g/day group associated with proximal colon endoscopic improvement. No severe side effect was observed in all 37 patients within 28 days. Furthermore, oral-delivered AVX-470 also demonstrated reduced systemic exposure in the blood (Harris et al., 2016). However, this study did not attempt to distinguish between AVX470 and endorsed infliximab. To the best of our knowledge, no further clinical study has been conducted. V565 is a $12.6-\mathrm{kDa}$ anti-TNF- $\alpha$ heavy chain variable domain antibody. It is isolated from a phage library produced from lymphocytes of a human TNF- $\alpha$ hyperimmunized llama and engineered to be resistant to intestinal and inflammatory proteases while retaining the TNF- $\alpha$ neutralizing potency against both soluble and membrane forms of human TNF- $\alpha$ (Crowe et al., 2017; Nurbhai et al., 2019). Opposite to AVX-470, V565 is unable to survive in acidic stomach environment and requires sustenance from oral delivery vehicles. In one in vivo study, DSS-induced colitis mice were administered with $140 \mu \mathrm{g}$ V565 by oral gavage after given a gastroprotective vehicle $\left(0.1 \mathrm{M} \mathrm{NaHCO}_{3}\right.$ containing $400 \mathrm{mg} / \mathrm{ml}$ Marvel milk). V565 transited well through the mouse GIT reaching high concentration within the lower GI tract and feces up to $7 \mathrm{~h}$ postdosing. In this study, treatment with V565 also inhibited inflammatory cytokines' production with maximal 
inhibitory effects similar to those achieved with the clinical positive control antibody adalimumab in vitro (Crowe et al., 2018). In another study based on the cynomolgus monkey model, oral V565 tablet coated with Eudragit enteric coat survived in the stomach and dissolved in the small intestine. Despite very high V565 concentrations in these monkeys' intestines, serum V565 was only found at deficient levels because V565 poorly traversed the intact epithelium of normal animals (Crowe et al., 2019). The potential of V565 as oral treatment has been tested in both CD and UC clinically. In a phase I clinical study, local and systemic pharmacokinetics were investigated in four patients with ulcerative colitis. Eudragit-coated V565 was encapsulated in hydroxypropyl methylcellulose (HPMC) capsules. Overall, this study showed that oral-delivered active V565 reaches IBD disease sites in high concentrations and can bind to V565 TNF- $\alpha^{+}$ cells in UC lesions (Nurbhai et al., 2019). In another phase I clinical study, 47 patients with CD were involved in investigating tolerability and safety of oral V565, and V565 is currently under phase II clinical study in Europe and North America (Crowe et al., 2017).

Limited cases of antibody-loaded NPs were reported for IBD treatment in recent decades. Nanoparticles with a size of $100 \mathrm{~nm}$ illustrated a higher accumulation in the colon (Lamprecht et al., 2001). In one study, tannic acid and poly(ethylene glycol)containing polymer self-assembled supramolecular NPs with a particle size of approximately $100 \mathrm{~nm}$ were utilized for antiTNF- $\alpha$ antibody delivery (Wang et al., 2020). DSS effect on colon length can be suppressed by the treatment of oral-delivered infliximab nanoparticles. The biodistribution study showed a minimized systemic exposure with low accumulation in the liver (Wang et al., 2020). Liposomes and other bilayer structure vesicles (Lee and Feijen, 2012; Akbarzadeh et al., 2013; Zhang et al., 2019) are broadly applied for drug delivery purposes. Jung Min Kim and others reported a series of infliximab-loaded liposomes for oral IBD treatment. As a result, infliximab-loaded liposomes had better colitis improvement than the control group alongside with remarkably decreased TNF- $\alpha$ level in a DSSinduced mouse colitis model (Kim et al., 2020).

In recent studies, scientists endeavored to use engineered bacteria as vectors for therapeutic agents (Hosseinidoust et al., 2016). Lactococcus lactis (L. lactis) was originally isolated from plants where it maintained dormant and only became active and multiplied in the GIT after being consumed by ruminants (Song et al., 2017). L. lactis is regarded as a safe vector. It cannot, on ingestion, invade the tissues, nor does it ever cause infection in humans and, at the same time, convey any health benefit (Steidler and Rottiers, 2006). After the report of using Lactobacilli as live vaccine delivery vectors in 2002, L. lactis has been recognized as a compelling candidate to introduce foreign antigens or antibodies (Seegers, 2002). Genetically engineered L. actis secreting IL-10 was first reported for IBD treatment in mice and pig model (Steidler et al., 2000, 2003). Its oral formulation, AG011, have been getting involved in multiple clinical trials. Phases I and II clinical studies have been conducted in patients with moderate UC. In another phase I clinical trial, AG011 was reported to reduce systemic adverse drug reactions in patients with $C D$
(Braat et al., 2006). Genetically engineered L. lactis provided a robust oral delivery platform in IBD therapy. Up until now, versatile cytokines or antibodies have been recombined into L. lactis for oral IBD treatment. Vandenbroucke et al. (2010) engineered $L$. lactis to secrete monovalent and bivalent murine (m)TNF-neutralizing nanobodies as therapeutic proteins. In their study, oral administration of nanobody-secreting L. lactis made successful local delivery of anti-mTNF nanobodies at the colon and significantly reduced inflammation in mice with (DSS)induced chronic colitis. In addition, this approach was also successful in improving established enterocolitis in IL-10-/mice (Vandenbroucke et al., 2010). In another study, L. lactis carrying the $\mathrm{scFv}$ expression vector was administered by gavage to mice with DSS-induced colitis. After 4 days of treatment, animals showed a significant improvement in histological score and disease activity index compared with those of untreated animals (Chiabai et al., 2019). Namai et al. (2020) showed L. lactis was able to deliver IL-1 antagonists. It was exemplified that orally delivered $L$. lactis secreting IL-1 antagonist was able to alleviate inflammation in an acute DSS-induced colitis mouse model (Namai et al., 2020).

\section{Therapeutic Peptides}

Therapeutic peptides represent a unique class of pharmaceutical compounds containing intrinsic signaling molecules for many physiological functions. It presents a new opportunity for therapeutic intervention that closely mimics natural pathways (Lau and Dunn, 2018). Understanding of the efficacy of peptides is only comprehended in the recent two decades. Even though various peptides have been used for IBD treatment (Table 2), the oral delivery systems for these drugs remain deficient. In this section, we will present existing oral delivery systems for therapeutic peptides in IBD.

$\mathrm{KPV}$, a tripeptide composed of Lys-Pro-Val, possesses antiinflammatory properties associated with PepT1 and was lately regarded as a candidate for IBD therapy (Dalmasso et al., 2008; Viennois et al., 2016). KPV was reported to ease colitis by adding in drinking water at a concentration of $205 \mu \mathrm{g} /$ day in the DSSinduced mice model (Dalmasso et al., 2008). To fully exploit its therapeutic efficacy, several colitis-targeting systems were developed to colocalize KPV with inflammation tissue. Polymeric NPs loaded with KPV were reported by Laroui et al. (2010). In this study, KPV was encapsulated in NPs composed of polylactide (PLA) and PVA using a double-emulsion/solvent evaporation method. KPV-loaded NPs can be taken up via endocytosis, causing 12,000-fold lower delivered KPV concentration than that of KPV in free solution, with therapeutic efficacy (Laroui et al., 2010). Drug delivery systems composed of multiple components were also reported. Hyaluronic acid (HA) can selectively recognize CD44 receptors overexpressed on the surface of colonic epithelial cells and macrophages in colitis tissues. Xiao et al. (2017) fabricated HA-functionalized polymeric NPs for KPV which were further loaded into a chitosan-based hydrogel. This HA-KPV-NP/hydrogel system has the capacity to release HA-KPV-NPs in the colonic lumen and subsequently penetrate colitis tissues and enable KPV to be internalized into target cells (Xiao et al., 2017). In some studies, KPV was utilized 
TABLE 2 | Therapeutic peptides applied in IBD treatment.

Therapeutic peptides applied for IBD treatment

\begin{tabular}{|c|c|c|}
\hline Name & Mechanism for IBD & Delivery approach \\
\hline VIP (Lakhan and Kirchgessner, 2010; Dulari et al., 2020) & Modulates the immune system by binding to two G-protein-coupled VIP receptor & Oral \\
\hline Ac2-26 (Li et al., 2019) & Inhibitor of NF-кB & Oral delivery \\
\hline GLP-2 (Ivory et al., 2008) & Inhibiting ERK1/2, JNK1/2, NF-кB signaling pathways, and SOCS in STAT-3 signaling & Subcutaneous \\
\hline WKYMVm (Kim et al., 2013) & 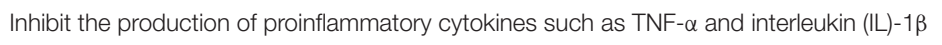 & Subcutaneous \\
\hline Adrenomedullin (Ashizuka et al., 2013) & Downregulation of inflammatory cytokines & NA \\
\hline Tyr-Pro-D-Ala-NH2-DI-1 (Salaga et al., 2018) & Regulate GLP-2 level & Intracolonic \\
\hline
\end{tabular}

as a part of the drug carrier. Wu et al. (2019) developed a colonspecific delivery system-PLGA-KPV/MMT/CS multifunctional medicinal nanoparticles loaded with cyclosporine A (CyA). In this study, KPV is utilized as a ligand for PepT1 to achieve targeting delivery. After being treated with the CyA-PLGAKPV/MMT/CS nanoparticles (PKMCN), the mice treated with DSS-induced colitis exhibited significant improvements in body weight, colon length, and disease activity index (Wu et al., 2019).

Vasoactive intestinal peptide (VIP) is a 28 -amino acid neuropeptide isolated from the intestine (Pozo et al., 2000). Elevated total VIP colonic level was found by radioimmunoassay in the $\mathrm{CD}$ tissues due to its modulation effect on cytokines (Abad et al., 2012; Zhang et al., 2016). Studies have validated the efficacy of VIP for IBD therapy in TNBS-induced colitis mice model via i.p. injection (Abad et al., 2003). Research on its oral delivery remains insufficient and only in vitro results are approachable. Dulari et al. (2020) constructed sterically stabilized micelles (VIP-SSM) for VIP's oral delivery and conducted in vitro release study of this potential oral formulation. However, further in vivo studies are required to validate its potency.

Ac2-26 is an annexin A1 N-terminal-derived peptide which can inhibit various aspects of the inflammatory response. Li et al. (2019) designed a reactive oxygen species responsive (ROS) delivery system for Ac2-26 which can selectively respond to abundant ROS in inflammation area and accomplish colitis targeting effect. In this study, orally delivered Ac2-26 effectively decreased the expression of proinflammatory mediators and reduced inflammation symptoms in both acute and chronic DSS-induced mice model (Li et al., 2019).

\section{Oligonucleotides}

Therapeutic oligonucleotides are synthesized nucleic acids interfering with the pathogenesis. Multiple forms of oligonucleotides are being applied in medical science, entailing different molecular mechanisms, including both inhibition of the translational process of messenger ribonucleic acid (mRNA) transcripts and mimicking bacterial deoxyribonucleic acid (DNA) which can activate cellular targets for immunomodulation (Scarozza et al., 2019; Smith and Zain, 2019). mRNA-silencing oligonucleotides are the main platforms studied for IBD treatment. This review will focus on introducing mRNAsilencing oligonucleotides in IBD treatment: siRNA and antisense oligonucleotide (AON).

Short-interfering RNAs are double-stranded RNA (dsRNA) which can suppress gene expression through a highly regulated enzyme-mediated process called RNA interference (RNAi), an endogenous pathway for posttranscriptional silencing of gene expression (Reynolds et al., 2004; Kanasty et al., 2013). dsRNAs are chopped up into 19-23 bp duplexes RNAs. One strand of these duplex RNA then binds to the RNA-induced silencing complex (RISC) and is unwind in an ATP-dependent manner. RISC mediates sequence-specific binding of these dsRNAs to a corresponding mRNA and catalyzes the cleavage and destruction of the mRNA by the enzyme slicer, enabling gene-specific silencing (Voinnet, 2005; Devi, 2006). siRNA in IBD treatment is designed to block mRNAs transcribing proinflammatory cytokines. However, siRNA can only activate after successful transfection which sets two hurdles on its further application (Wang et al., 2010). Firstly, siRNA is unstable in the circulation system with a very short plasma half-life of about 10 min (Takahashi et al., 2009). More importantly, siRNA can be only uptaken by targeting cells via endocytosis, and during its internalization, lysosomes can degrade siRNA (Tseng et al., 2009). Thus, colitis-targeting oral delivery is required to balance their ability to protect siRNA from degradation in cytoplasma and plasma and prolong its pharmacokinetics, to colocalize siRNA in inflammatory lesions which prevent potential interference of siRNA on healthy normal tissue and to guide siRNA to survive lysosome. These presurmises determined the extremely challenging nature of the oral siRNA delivery system for IBD treatment. Targeted natural NPs from edible plants are utilized for siRNA delivery in oral IBD treatment (Yang and Merlin, 2020). Active components in ginger such as 6-gingerol and 6-shogaol illustrated anti-inflammatory effects (Grzanna et al., 2005). Zhang et al. (2016) reported that ginger-derived nanoparticles (GDNPs) can ameliorate colitis syndromes and enhance the wound-healing process. The same group prepared ginger-derived lipid vehicles (GDLVs) out of GDNPs for siRNA delivery. GDLVs loaded with siRNACD98 effectively reduced the expression of CD98 in the colon and demonstrated a great potential for IBD treatment (Zhang et al., 2017). Kriegel and Amiji (2011a) reported a 
nanoparticle-in-microsphere oral system. TNF- $\alpha$ specific siRNA was encapsulated in type $B$ gelatin nanoparticles and further entrapped in poly(epsilon-caprolactone) (PCL) microspheres. Successful gene silencing led to decreased colonic levels of TNF- $\alpha$ and suppressed expression of other proinflammatory cytokines in DSS-induced colitis mice model (Kriegel and Amiji, 2011a). The same delivery system encapsulated with a combination of siRNA duplexes specifically targeted against TNF- $\alpha$ and cyclin D was also reported (Kriegel and Amiji, 2011b). Mitogen-activated protein kinase kinase kinase kinase 4 (Map4k4) has been demonstrated to be a key upstream mediator of TNF- $\alpha$ action (Aouadi et al., 2009). Zhang et al. (2013) reported that galactosylated trimethyl chitosan-cysteine (GTC) NPs for oral delivery of a Map4k4 siRNA (siMap4k4) activated macrophages and demonstrated therapeutic efficacy in DSS-induced colitis mice model. Knipe et al. (2016) designed a platform consisting of microgels composed of poly(methacrylic acid-co- $N$-vinyl-2-pyrrolidone) (P[MAA-co-NVP]) cross-linked with a trypsin-degradable peptide linker. This $\mathrm{pH}$-responsive microencapsulated nanogel can protect TNF alpha-siRNA against gastrointestinal environment (Knipe et al., 2016). Wilson et al. (2010) developed thioketal nanoparticles for oral delivery of anti-TNF- $\alpha$ siRNA. Nanoparticles can protect siRNA from degradation in the stomach until it reacts with abnormally high ROS in inflammation areas in the colon more precisely colocalization of therapeutic gene and inflammatory lesion.

Antisense oligonucleotide are single-stranded DNA molecules binding to complementary mRNA by base pairing and induce cleavage of targeted mRNA by ribonuclease $\mathrm{H}$, an enzyme that degrades RNA in RNA-DNA duplexes, leading to decreased gene expression (Kole et al., 2012; Di Fusco et al., 2019). In contrast to siRNA, which tolerates only minimum modifications to remain its efficacy, more extensive chemical modifications do not abrogate RNase $\mathrm{H}$ activity on antisense DNA-RNA complexes (Kole et al., 2012). Phosphorothioate (PS) is one of the most common methods to stabilize antisense oligonucleotide which provides increased resistance to the nucleases thereby extending AON's half-lives (Crooke, 2007). More importantly, PS induces protein adsorption on the AON strand which further prevents rapid AON clearance by glomerular filtration (Crooke, 2007). Mongersen (GED0301) is a formulation containing a 21base single-strand phosphorothioate oligonucleotide targeting SMAD7, an intracellular protein associated with abnormal cytokine deficiency in CD patients (Monteleone et al., 2001, 2015; Ardizzone et al., 2016). A preclinical study demonstrated that mongersen facilitates TGF- $\beta 1$-mediated suppression of colitis after oral administration with bicarbonate in the TNBS inducedcolitis mice model (Boirivant et al., 2006). In several clinical studies, morgersen is encapsulated in the modified tablet to achieve controlled release in the lumen of the terminal ileum and right colon (Ardizzone et al., 2016). In a double-blind, placebo-controlled, phase 2 trial, 188 patients with moderateto-severe CD were enrolled in this study. The rate of clinical response was significantly greater among patients receiving $10 \mathrm{mg}$ (37\%), $40 \mathrm{mg}$ (58\%), or $160 \mathrm{mg}$ (72\%) of mongersen than among those receiving placebo (17\%) (Monteleone et al., 2015). However, in the report of the newest phase 3 clinical trials, proportions of patients achieving clinical remission at week 52 were similar among individual morgersen groups and placebo at study termination (Sands et al., 2020). AONs with other pharmacological targets are also investigated though very few studies have focused on their oral delivery (Table 3). To the best of our knowledge, only one NP has been designed for oral delivery of AON in IBD treatment. In this study, AON against TNF- $\alpha$ was delivered via polysaccharide-based NPs. The oral-delivered NPs reduce TNF- $\alpha$ production by $36.4 \%$ in DSSinduced mice model (Duan et al., 2019).

\section{Gene Therapy}

Gene therapy is described as products that mediate their effects by transcription and/or translation of transferred genetic material and/or by integrating into the host genome (Wirth et al., 2013). It was hypothesized that in contrast to protein-based drugs that may require repeated infusion, gene-based therapies might maintain sustained production of endogenous proteins, such as clotting factors in hemophilia (High and Anguela, 2016; Dunbar et al., 2018). Like any other oligonucleotides, gene therapy components will degrade in physiological condition and cannot transfect targeted cells spontaneously. Vectors are required for successful gene therapy delivery. Viruses are naturally designed to repose their nucleic acid into living cells. It was reported that a topically delivered pseudo-typed lentivirus vector encoding murine IL-10 successfully penetrated local mucosal tissue and had therapeutic benefits in DSS-induced mice model (Matsumoto et al., 2014). In another study, recombinant adenoviruses are used as the vector for peroxisome proliferator-activated receptor (PPAR) $\gamma$ gene therapy (Katayama et al., 2003). Activation of PPAR $\gamma$ in the intestinal tissues plays an anti-inflammatory role against colitis (Su et al., 1999). In this study, low tissue levels of PPAR $\gamma$ can be reversed by gene therapy allowing for a therapeutic response via i.p. injection (Katayama et al., 2003). No evidence supported viral vectors can be delivered via oral administration according to the best of our knowledge. This may be partially due to their immunogenicity and susceptibility toward the gastrointestinal environment including the gastrointestinal lumen and the intestinal mucosa. Scientists also used bacteria such as E. coli as alternatives for oral-delivered gene therapy (Castagliuolo et al., 2005). Palffy et al. (2011) selected bacteria, Salmonella, to carry plasmids with genes encoding $\mathrm{Cu}-\mathrm{Zn}$ superoxide dismutase and

TABLE 3 | Antisense oligonucleotides in IBD treatment.

Antisense oligonucleotides for IBD treatment

\begin{tabular}{ll}
\hline Target of AONs & $\begin{array}{l}\text { Administration } \\
\text { approach }\end{array}$ \\
\hline $\begin{array}{l}\text { Intracellular adhesion molecule-1 } \\
\text { (alicaforsen) (Jairath et al., 2017) }\end{array}$ & Intravenous, rectal \\
Inhibition of Smad7 (mongersen) & Oral \\
(Boirivant et al., 2006) & \\
NF-kBp65 (Murano et al., 2000) & Intracolonic \\
Blocking CD154/CD40 interactions & Intracolonic \\
(Gao et al., 2005) & \\
TNF- $\alpha$ (Duan et al., 2019) & Oral
\end{tabular}


an N-terminal deletion mutant of monocyte chemoattractant protein-1 for oral delivery. This approach alleviated colitis in DSS-induced mice models (Palffy et al., 2011). Non-viral vectors such as lipid nanoparticles (LNP) are another major tool for gene therapy (del Pozo-Rodríguez et al., 2016). By selecting biocompatible materials, those non-viral vectors can elude the immunogenicity of viral vectors. Bhavsar and Amiji (2008) reported an oral-delivered gene therapy using non-viral vectors. This study used a nanoparticle-in-microsphere oral system (NiMOS) loaded with murine IL-10-expressing plasmid DNA in type-B gelatin nanoparticles. As a result, local-transfected IL-10 was very effective in reducing the levels of proinflammatory cytokines and demonstrated therapeutic effect in the TNBSinduced colitis model (Bhavsar and Amiji, 2008).

\section{FUTURE PERSPECTIVES}

Colitis targeting via the oral route has demonstrated favorable properties including increased patients' compliance, reduced ADRs, and enhanced drug concentration in inflammatory lesions. Current oral delivery systems for biologics in IBD therapy are designed to meet two fundamental requirements: secured transition of biologics in the gastrointestinal environment and decreased systemic exposure while maintaining therapeutic efficacy. Yet only four oral biologic formulations (AVX-570, V565, AG011, and mongersen) have been transited into clinical study, and none of them have been approved. In this section, we provide with several perspectives that may guide the advancement of oral delivery system in the future study.

With a more comprehensive understanding on the pathogenesis process of IBD, more types of biologics are added into the therapeutic armamentarium. However, current oral delivery systems are scarce to cover all these reagents. For instance, most studies on oral-delivered antibodies were focused on anti-TNF- $\alpha$ antibodies, and to the best of our knowledge, no oral delivery system has been designed for antiadhesion or antiIL antibodies. The similar unmet requirement is observed for therapeutic peptides. Furthermore, the current design strategy for oral-delivered biologics carry two major drawbacks: (1) the complexity of an oral delivery system can create barriers to their transition to clinical study and industrialized fabrication and (2) oral drug delivery systems for antibodies should keep a large drug capacity to neglect the effect of antidrug antibody, which, oppositely, is undermined by the encapsulation procedure. Some of the aspects can be enhanced. NPs for biologics in IBD treatment passively accumulate in the colon via a size-dependent mechanism. As mentioned in the former section, $100 \mathrm{~nm}$ NPs demonstrated the highest accumulation in the colon whereas many of NPs designed for oral delivery have a size two- to fivefold larger. Besides, NPs can be modified with different molecules to achieve active targeting such as lectin to selectively bind to the Thomsen-Friedenreich (TF) blood group antigen in the colon (Ryder et al., 1998; Moulari et al., 2014). L. lactis is a substantial tool for the oral antibody delivery in IBD therapy. Accordingly, it can also carry other biologics such as therapeutic peptides (Agarwal et al., 2014). In addition, new formulations for oral biologics should be added. Some topical formulations demonstrated great potential in IBD treatment and can be transferred into oral delivery. Adhesive patches are able to adhere to mucus and was used widely as a topical delivery system for the oral cavity (Nafee et al., 2003). Oral-delivered intestinal adhesive patches were developed for insulin delivery and can be an interesting candidate for IBD therapy (Gupta et al., 2013). Rectal foam has been clinically applied in IBD treatment for the delivery of hydrocortisone and mesalazine. Its expansion and retention ability provide sufficient covered area and enhanced drug concentration in the interface between foam and inflammatory tissue (Arévalo-Pérez et al., 2020). Oral-delivered foam is an interesting concept with very rare evidence to validate (Haznar-Garbacz et al., 2019). So far, oral delivery of biologics is still an unmet medical need for IBD treatment requiring further development.

Inflammatory bowel disease involves very convoluted pathogenesis, and so far, no existing animal model can precisely simulate its pathological conditions (Wirtz and Neurath, 2007). Gene-engineered IBD mice models including gene knockout mice, transgenic, and spontaneous colitis models can help assess the efficacy of therapeutic reagent in IBD considering one of its pathogenesis aspects (Lindsay et al., 2003; Jurjus et al., 2004). However, implementation of these models is expensive and time consuming, constraining their application in screening of therapeutic biologics, and inducible colitis models are applied more ubiquitously. Nevertheless, each of these models can only emphasize on one aspect of the mechanism of the disease. It is believed that the DSS-induced colitis model is particularly useful to study the contribution of innate immune mechanisms of colitis (Wirtz and Neurath, 2007) while in chronic TNBS colitis, CD4+ T cells have been shown to play a central role (Neurath et al., 1995). Many of the studies only use one single model to assess the efficacy of the delivery system though distinguished aspects from different models should be taken into consideration. On contrast to some of the current studies, repetitive multiple dosages of biologics are required in clinic for IBD treatment. In our view, acute IBD model accentuate illustration of in vivo mechanism of biologics and chronic colitis models are more potent tools to validate biological therapeutic efficacy. Other than in vivo mice models, some newly established in vitro models demonstrated favorable characteristics in IBD study and can provide patientspecified information in screening of therapeutic biologics. Intestinal organoids are complex three-dimensional structures that mimic the cell-type composition and tissue organization of the intestine derived from the isolation and culture of primary stem cells of intestinal crypts or iPSCs (Serra et al., 2019; Angus et al., 2020). These organoids can be expanded from intestinal tissue samples of healthy and IBD mucosa in both adult and pediatric patient which render improved physiological accuracy model for dissecting IBD pathogenesis and personalized high-throughput screening for new biologics (Dotti and Salas, 2018).

Multiple parameters have settled as standards to assess colitis severity in mice, including clinical activity score assessing weight loss, stool consistency, rectal bleeding, colon length, 
histological assessment, endoscopy or colonoscopy images, or concentration of multiple cytokines or inflammatory biomarkers such as myeloperoxidase. New evaluation standards can bring innovative perspectives and achieve a better understanding for the biological therapeutic effect. Oral delivered biologics have a potential problem of drug lost in stool yet very rare of researchers have evaluated this aspect. Feces drug concentration can be vital to explain low efficacy of certain oral delivery system for biologics (Brandse et al., 2015). Gut microbiota is a newly recognized factor playing an essential role in IBD development. It was reported that short-term treatment with enterically coated antibiotics dramatically reduced intestinal inflammation. The relevance of microbiota in IBD is also illustrated in a report where reduced microbiota diversity was observed in the fecal microbiome in patients with CD compared with healthy control (Manichanh et al., 2006). The evaluation of the effect of a biological formulation on gut microbiota can provide a unique perspective on their efficacy. Organoid in 2D culture such as the air-liquid interface cultures of the intestinal stem have been used as an established model to study host-microbiota interactions in IBD (Wang et al., 2015; Dotti and Salas, 2018). It will be an illustrative tool for research on formulation-microbiota interaction. Gut-on-chip is another state-in-art invention that can be utilized in IBD therapy (Kim et al., 2016; Poceviciute and Ismagilov, 2019). It can more closely represent the $3 \mathrm{D}$ structure and physiological microenvironment of native tissues

\section{REFERENCES}

Abad, C., Gomariz, R., Waschek, J., Leceta, J., Martinez, C., Juarranz, Y., et al. (2012). VIP in inflammatory bowel disease: state of the art. Endocr. Metab. Immune Disord. Drug Targets 12, 316-322. doi: 10.2174/187153012803832576

Abad, C., Martinez, C., Juarranz, M. G., Arranz, A., Leceta, J., Delgado, M., et al. (2003). Therapeutic effects of vasoactive intestinal peptide in the trinitrobenzene sulfonic acid mice model of Crohn's disease. Gastroenterology 124, 961-971. doi: 10.1053/gast.2003.50141

Agarwal, P., Khatri, P., Billack, B., Low, W.-K., and Shao, J. (2014). Oral delivery of glucagon like peptide-1 by a recombinant Lactococcus lactis. Pharm. Res. 31, 3404-3414. doi: 10.1007/s11095-014-1430-3

Agrawal, M., Kim, E. S., and Colombel, J.-F. (2020). JAK inhibitors safety in ulcerative colitis: practical implications. J. Crohns Colitis 14(Suppl. 2), S755S760.

Akbarzadeh, A., Rezaei-Sadabady, R., Davaran, S., Joo, S. W., Zarghami, N., Hanifehpour, Y., et al. (2013). Liposome: classification, preparation, and applications. Nanoscale Res. Lett. 8, 1-9.

Amiot, A., and Peyrin-Biroulet, L. (2015). Current, new and future biological agents on the horizon for the treatment of inflammatory bowel diseases. Ther. Adv. Gastroenterol. 8, 66-82. doi: 10.1177/1756283x14558193

Ananthakrishnan, A. N., Bernstein, C. N., Iliopoulos, D., Macpherson, A., Neurath, M. F., Ali, R. A. R., et al. (2018). Environmental triggers in IBD: a review of progress and evidence. Nat. Rev. Gastroenterol. Hepatol. 15:39. doi: 10.1038/ nrgastro.2017.136

Angus, H. C. K., Butt, A. G., Schultz, M., and Kemp, R. A. (2020). Intestinal organoids as a tool for inflammatory bowel disease research. Front. Med. 6:334. doi: 10.3389/fmed.2019.00334

Anselmo, A. C., Gokarn, Y., and Mitragotri, S. (2019). Non-invasive delivery strategies for biologics. Nat. Rev. Drug Discov. 18, 19-40. doi: 10.1038/nrd.2018. 183

Aouadi, M., Tesz, G. J., Nicoloro, S. M., Wang, M., Chouinard, M., Soto, E., et al. (2009). Orally delivered siRNA targeting macrophage Map4k4 suppresses systemic inflammation. Nature 458, 1180-1184. doi: 10.1038/nature07774 by incorporating live cells into microfluidic platforms and demonstrate host-pathogen interactions in IBD pathogenesis (Lee et al., 2016; Ashammakhi et al., 2020).

Altogether, colitis targeting via oral delivery remains a promising strategy with potential to refine biological therapy in IBD treatment. It may be capable of providing new clinical strategies for biologic delivery due to reduced ADRs and increase local drug concentration. Remaining an unfulfilled task, the development of oral delivery systems for biologics in IBD treatment still requires ingenious inspiration and assiduous study.

\section{AUTHOR CONTRIBUTIONS}

WZ, $C M$, and $A B$ designed the structure of the manuscript. WZ and $\mathrm{CM}$ wrote the first draft. $\mathrm{AB}, \mathrm{WZ}$, and $\mathrm{CM}$ corrected and edited the manuscript. All the authors contributed to the article and approved the submitted version.

\section{FUNDING}

WZ is a F.R.S.-FNRS FRIA Ph.D. fellow. AB is a research associate from the F.R.S.-FNRS. This work was supported by the F.R.S.FNRS (convention T.0013.19) and Fonds Spéciaux de Recherche from the UCLouvain.
Ardizzone, S., Bevivino, G., and Monteleone, G. (2016). Mongersen, an oral Smad7 antisense oligonucleotide, in patients with active Crohn's disease. Ther. Adv. Gastroenterol. 9, 527-532. doi: 10.1177/1756283x166 36781

Arévalo-Pérez, R., Maderuelo, C., and Lanao, J. M. (2020). Recent advances in colon drug delivery systems. J. Control. Release 327, 703-724.

Ashammakhi, N., Nasiri, R., Barros, NRd, Tebon, P., Thakor, J., Goudie, M., et al. (2020). Gut-on-a-chip: current progress and future opportunities. Biomaterials 255:120196. doi: 10.1016/j.biomaterials.2020.120196

Ashizuka, S., Inatsu, H., Inagaki-Ohara, K., Kita, T., and Kitamura, K. (2013). Adrenomedullin as a potential therapeutic agent for inflammatory bowel disease. Curr. Protein Peptide Sci. 14, 246-255. doi: 10.2174/ 13892037113149990044

Baumgart, D. C., and Carding, S. R. (2007). Inflammatory bowel disease: cause and immunobiology. Lancet. 369, 1627-1640. doi: 10.1016/s0140-6736(07)60750-8

Beloqui, A., Coco, R., and Preat, V. (2016). Targeting inflammatory bowel diseases by nanocarriers loaded with small and biopharmaceutical antiinflammatory drugs. Curr. Pharm. Design 22, 6192-6206. doi: 10.2174/ 1381612822666160211141813

Beloqui, A., Coco, R., Memvanga, P. B., Ucakar, B., des Rieux, A., and Préat, V. (2014). pH-sensitive nanoparticles for colonic delivery of curcumin in inflammatory bowel disease. Int. J. Pharm. 473, 203-212. doi: 10.1016/j. ijpharm.2014.07.009

Ben-Horin, S., and Chowers, Y. (2011). Review article: loss of response to antiTNF treatments in Crohn's disease. Aliment Pharmacol. Ther. 33, 987-995. doi: 10.1111/j.1365-2036.2011.04612.x

Bernstein, C. N. (2015). Treatment of IBD: where we are and where we are going. Am. J. Gastroenterol. 110, 114-126. doi: 10.1038/ajg.2014.357

Bhavsar, M. D., and Amiji, M. M. (2008). Oral IL-10 gene delivery in a microsphere-based formulation for local transfection and therapeutic efficacy in inflammatory bowel disease. Gene Ther. 15, 1200-1209. doi: 10.1038/gt.2008. 67

Bhol, K. C., Tracey, D. E., Lemos, B. R., Lyng, G. D., Erlich, E. C., Keane, D. M., et al. (2013). AVX-470: a novel oral anti-TNF antibody with therapeutic potential in 
inflammatory bowel disease. Inflamm. Bowel Dis. 19, 2273-2281. doi: 10.1097/ mib.0b013e3182a11958

Boirivant, M., Pallone, F., Di Giacinto, C., Fina, D., Monteleone, I., Marinaro, M., et al. (2006). Inhibition of Smad7 with a specific antisense oligonucleotide facilitates TGF- $\beta 1-$ Mediated suppression of colitis. Gastroenterology $131,1786-$ 1798. doi: $10.1053 /$ j.gastro.2006.09.016

Braat, H., Rottiers, P., Hommes, D. W., Huyghebaert, N., Remaut, E., Remon, J. P., et al. (2006). A phase I trial with transgenic bacteria expressing interleukin-10 in Crohn's disease. Clin. Gastroenterol. Hepatol. 4, 754-759. doi: 10.1016/j.cgh. 2006.03.028

Brandse, J. F., van den Brink, G. R., Wildenberg, M. E., van der Kleij, D., Rispens, T., Jansen, J. M., et al. (2015). Loss of infliximab into feces is associated with lack of response to therapy in patients with severe ulcerative colitis. Gastroenterology 149, 350-355.e2.

Castagliuolo, I., Beggiao, E., Brun, P., Barzon, L., Goussard, S., Manganelli, R., et al. (2005). Engineered E. coli delivers therapeutic genes to the colonic mucosa Gene Ther. 12, 1070-1078. doi: 10.1038/sj.gt.3302493

Chen, S-q, Song, Y-q, Wang, C., Tao, S., Yu, F.-Y., Lou, H.-Y., et al. (2020). Chitosan-modified lipid nanodrug delivery system for the targeted and responsive treatment of ulcerative colitis. Carbohydrate Polym. 230:115613. doi: 10.1016/j.carbpol.2019.115613

Chiabai, M. J., Almeida, J. F., de Azevedo, M. G. D., Fernandes, S. S., Pereira, V. B., de Castro, R. J. A., et al. (2019). Mucosal delivery of Lactococcus lactis carrying an anti-TNF scFv expression vector ameliorates experimental colitis in mice. BMC Biotechnol. 19:38. doi: 10.1186/s12896-019-0518-6

Cholapranee, A., Hazlewood, G. S., Kaplan, G. G., Peyrin-Biroulet, L., and Ananthakrishnan, A. N. (2017). Systematic review with meta-analysis: comparative efficacy of biologics for induction and maintenance of mucosal healing in Crohn's disease and ulcerative colitis controlled trials. Alimentary Pharmacol. Ther. 45, 1291-1302. doi: 10.1111/apt.14030

Cohen, R. D., and Dalal, S. R. (2015). Systematic review: rectal therapies for the treatment of distal forms of ulcerative colitis. Inflamm. Bowel Dis. 21, 1719-1736. doi: 10.1097/mib.0000000000000379

Crooke, S. T. (2007). Antisense Drug Technology: Principles, Strategies, and Applications. Boca Raton, FL: CRC Press

Crowe, J. S., Roberts, K. J., Carlton, T. M., Maggiore, L., Cubitt, M. F., Clare, S., et al. (2018). Preclinical development of a novel, orally-administered antitumour necrosis factor domain antibody for the treatment of inflammatory bowel disease. Sci. Rep. 8:4941.

Crowe, J. S., Roberts, K. J., Carlton, T. M., Maggiore, L., Cubitt, M. F., Ray, K. P., et al. (2019). Oral delivery of the anti-tumor necrosis factor $\alpha$ domain antibody, V565, results in high intestinal and fecal concentrations with minimal systemic exposure in cynomolgus monkeys. Drug Dev. Ind. Pharm. 45, 387-394. doi: 10.1080/03639045.2018.1542708

Crowe, S., West, M., Roberts, K., Carlton, T., Maggiore, L., Cubitt, M. eds, et al. (2017). "Preclinical assessment of a novel Anti-TNF $\alpha$ Vorabody ${ }^{\mathrm{TM}}$ as an oral therapy for Crohn's disease," in Proceedings of the 18th International Congress of Mucosal Immunology. (Cambridge: VHsquared)

Dahan, A., Amidon, G. L., and Zimmermann, E. M. (2010). Drug targeting strategies for the treatment of inflammatory bowel disease: a mechanistic update. Expert Rev. Clin. Immunol. 6, 543-550. doi: 10.1586/eci.10.30

Dalmasso, G., Charrier-Hisamuddin, L., Nguyen, H. T. T., Yan, Y., Sitaraman, S., and Merlin, D. (2008). PepT1-mediated tripeptide KPV uptake reduces intestinal inflammation. Gastroenterology 134, 166-178. doi: 10.1053/j.gastro. 2007.10.026

Danese, S., Vuitton, L., and Peyrin-Biroulet, L. (2015). Biologic agents for IBD: practical insights. Nat. Rev. Gastroenterol. Hepatol. 12:537. doi: 10.1038/ nrgastro.2015.135

De Souza, H. S., and Fiocchi, C. (2016). Immunopathogenesis of IBD: current state of the art. Nat. Rev. Gastroenterol. Hepatol. 13:13. doi: 10.1038/nrgastro.2015. 186

del Pozo-Rodríguez, A., Solinís, M. Á, and Rodríguez-Gascón, A. (2016). Applications of lipid nanoparticles in gene therapy. Eur. J. Pharm. Biopharm. 109, 184-193. doi: 10.1016/j.ejpb.2016.10.016

Devi, G. R. (2006). siRNA-based approaches in cancer therapy. Cancer Gene Ther. 13, 819-829. doi: 10.1038/sj.cgt.7700931

Di Fusco, D., Dinallo, V., Marafini, I., Figliuzzi, M. M., Romano, B., and Monteleone, G. (2019). Antisense oligonucleotide: basic concepts and therapeutic application in inflammatory bowel disease. Front. Pharmacol. 10:305. doi: 10.3389/fphar.2019.00305

Doherty, G. A., and Peppercorn, M. A. (2009). Update on the role of modified release mesalamine in the management of ulcerative colitis and Crohn's disease. Clin. Exp. Gastroenterol. 2:139. doi: 10.2147/ceg.s6145

Dotti, I., and Salas, A. (2018). Potential use of human stem cell-derived intestinal organoids to study inflammatory bowel diseases. Inflamm. Bowel Dis. 24, 2501-2509.

Duan, B., Li, M., Sun, Y., Zou, S., and Xu, X. (2019). Orally delivered antisense oligodeoxyribonucleotides of TNF- $\alpha$ via polysaccharide-based nanocomposites targeting intestinal inflammation. Adv. Healthcare Mater. 8:1801389. doi: 10. 1002/adhm.201801389

Dulari, J., Anbazhagan, A. N., Priyamvada, S., Kumar, A., Saksena, S., Onyuksel, H., et al. (2020). Colonic delivery of vasoactive intestinal peptide nanomedicine alleviates colitis and shows promise as an oral capsule. Nanomedicine 15, 2459-2474. doi: 10.2217/nnm-2020-0280

Dunbar, C. E., High, K. A., Joung, J. K., Kohn, D. B., Ozawa, K., and Sadelain, M. (2018). Gene therapy comes of age. Science 359:6372.

Eiamtrakarn, S., Itoh, Y., Kishimoto, J., Yoshikawa, Y., Shibata, N., Murakami, M., et al. (2002). Gastrointestinal mucoadhesive patch system (GI-MAPS) for oral administration of G-CSF, a model protein. Biomaterials 23, 145-152. doi: 10.1016/s0142-9612(01)00089-8

Gao, D., Wagner, A. H., Fankhaenel, S., Stojanovic, T., Schweyer, S., Panzner, S., et al. (2005). CD40 antisense oligonucleotide inhibition of trinitrobenzene sulphonic acid induced rat colitis. Gut 54:70. 10.1136/gut.2003. 029587

Ghosh, S., and Panaccione, R. (2010). Anti-adhesion molecule therapy for inflammatory bowel disease. Therap. Adv. Gastroenterol. 3, 239-258. doi: 10. $1177 / 1756283 \times 10373176$

Gonzalez-Rey, E., Varela, N., Sheibanie, A. F., Chorny, A., Ganea, D., and Delgado, M. (2006). Cortistatin, an antiinflammatory peptide with therapeutic action in inflammatory bowel disease. Proc. Natl. Acad. Sci. U.S.A. 103:4228. doi: 10.1073/pnas.0508997103

Grzanna, R., Lindmark, L., and Frondoza, C. G. (2005). Ginger-an herbal medicinal product with broad anti-inflammatory actions. J. Med. Food 8, 125-132. doi: 10.1089/jmf.2005.8.125

Guan, Q., and Zhang, J. (2017). Recent advances: the imbalance of cytokines in the pathogenesis of inflammatory bowel disease. Med. Inflamm. 2017:4810258.

Guo, X. Y., Liu, X. J., and Hao, J. Y. (2020). Gut microbiota in ulcerative colitis: insights on pathogenesis and treatment. J. Digest. Dis. 21, 147-159. doi: 10. 1111/1751-2980.12849

Gupta, V., Hwang, B. H., Lee, J., Anselmo, A. C., Doshi, N., and Mitragotri, S. (2013). Mucoadhesive intestinal devices for oral delivery of salmon calcitonin. J. Control. Release 172, 753-762. doi: 10.1016/j.jconrel.2013.09.004

Hanauer, S. B. (2010). Advantages in IBD: current developments in the treatment of inflammatory bowel diseases. Gastroenterol. Hepatol. 6, 309-316.

Harris, M. S., Hartman, D., Lemos, B. R., Erlich, E. C., Spence, S., Kennedy, S., et al. (2016). AVX-470, an orally delivered anti-tumour necrosis factor antibody for treatment of active ulcerative colitis: results of a first-in-human trial. J. Crohns Colitis. 10, 631-640. doi: 10.1093/ecco-jcc/jjw036

Haznar-Garbacz, D., Garbacz, G., and Weitschies, W. (2019). Development of oral foams for topical treatment of inflammatory bowel disease. J. Drug Deliv. Sci. Technol. 50, 287-292. doi: 10.1016/j.jddst.2019.01.022

High, K. A., and Anguela, X. M. (2016). Adeno-associated viral vectors for the treatment of hemophilia. Hum. Mol. Genet. 25, R36-R41.

Hosseinidoust, Z., Mostaghaci, B., Yasa, O., Park, B.-W., Singh, A. V., and Sitti, M. (2016). Bioengineered and biohybrid bacteria-based systems for drug delivery. Adv. Drug Deliv. Rev. 106, 27-44. doi: 10.1016/j.addr.2016.09.007

Hua, S., Marks, E., Schneider, J. J., and Keely, S. (2015). Advances in oral nanodelivery systems for colon targeted drug delivery in inflammatory bowel disease: selective targeting to diseased versus healthy tissue. Nanomedicine 11, 11171132. doi: 10.1016/j.nano.2015.02.018

Ivory, C. P. A., Wallace, L. E., McCafferty, D.-M., and Sigalet, D. L. (2008). Interleukin-10-independent anti-inflammatory actions of glucagon-like peptide 2. Am. J. Physiol. Gastrointestinal Liver Physiol. 295, G1202-G1210.

Jairath, V., Khanna, R., and Feagan, B. G. (2017). Alicaforsen for the treatment of inflammatory bowel disease. Expert Opin. Invest. Drugs 26, 991-997. doi: $10.1080 / 13543784.2017 .1349753$ 
Ju, S., Mu, J., Dokland, T., Zhuang, X., Wang, Q., Jiang, H., et al. (2013). Grape exosome-like nanoparticles induce intestinal stem cells and protect mice from DSS-induced colitis. Mol. Ther. 21, 1345-1357. doi: 10.1038/mt.2013.64

Jurjus, A. R., Khoury, N. N., and Reimund, J.-M. (2004). Animal models of inflammatory bowel disease. J. Pharmacol. Toxicol. Methods 50, 81-92.

Kanaan, Z., Rai, S. N., Eichenberger, M. R., Barnes, C., Dworkin, A. M., Weller, C., et al. (2012). Differential MicroRNA expression tracks neoplastic progression in inflammatory bowel disease-associated colorectal cancer. Hum. Mutat. 33, 551-560. doi: 10.1002/humu.22021

Kanasty, R., Dorkin, J. R., Vegas, A., and Anderson, D. (2013). Delivery materials for siRNA therapeutics. Nat. Mater. 12, 967-977. doi: 10.1038/nmat3765

Katayama, K., Wada, K., Nakajima, A., Mizuguchi, H., Hayakawa, T., Nakagawa, S., et al. (2003). A novel PPAR $\gamma$ gene therapy to control inflammation associated with inflammatory bowel disease in a murine model. Gastroenterology 124, 1315-1324. doi: 10.1016/s0016-5085(03)00262-2

Katsanos, K. H., Papamichael, K., Feuerstein, J. D., Christodoulou, D. K., and Cheifetz, A. S. (2019). Biological therapies in inflammatory bowel disease: beyond anti-TNF therapies. Clin. Immunol. 206, 9-14. doi: 10.1016/j.clim.2018. 03.004

Kennedy, N. A., Heap, G. A., Green, H. D., Hamilton, B., Bewshea, C., Walker, G. J., et al. (2019). Predictors of anti-TNF treatment failure in anti-TNF-naive patients with active luminal Crohn's disease: a prospective, multicentre, cohort study. Lancet Gastroenterol. Hepatol. 4, 341-353.

Kesisoglou, F., and Zimmermann, E. M. (2005). Novel drug delivery strategies for the treatment of inflammatory bowel disease. Expert Opin. Drug Deliv. 2, 451-463. doi: 10.1517/17425247.2.3.451

Khan, I., Ullah, N., Zha, L., Bai, Y., Khan, A., Zhao, T., et al. (2019). Alteration of gut microbiota in inflammatory bowel disease (IBD): cause or consequence? IBD treatment targeting the gut microbiome. Pathogens 8:126. doi: 10.3390/ pathogens 8030126

Khor, B., Gardet, A., and Xavier, R. J. (2011). Genetics and pathogenesis of inflammatory bowel disease. Nature 474, 307-317.

Kim, H. J., Li, H., Collins, J. J., and Ingber, D. E. (2016). Contributions of microbiome and mechanical deformation to intestinal bacterial overgrowth and inflammation in a human gut-on-a-chip. Proc. Natl. Acad. Sci. U.S.A. 113, E7-E15.

Kim, J. M., Kim, D. H., Park, H. J., Ma, H. W., Park, I. S., Son, M., et al. (2020). Nanocomposites-based targeted oral drug delivery systems with infliximab in a murine colitis model. J. Nanobiotechnol. 18, 1-13.

Kim, S. D., Kwon, S., Lee, S. K., Kook, M., Lee, H. Y., Song, K.-D., et al. (2013). The immune-stimulating peptide WKYMVm has therapeutic effects against ulcerative colitis. Exp. Mol. Med. 45:e40. doi: 10.1038/emm.2013.77

Knipe, J. M., Strong, L. E., and Peppas, N. A. (2016). Enzyme- and pH-Responsive microencapsulated nanogels for oral delivery of siRNA to induce TNF- $\alpha$ knockdown in the intestine. Biomacromolecules 17, 788-797. doi: 10.1021/acs. biomac. 5 b01518

Ko, C. W., Singh, S., Feuerstein, J. D., Falck-Ytter, C., Falck-Ytter, Y., Cross, R. K., et al. (2019). AGA clinical practice guidelines on the management of mildto-moderate ulcerative colitis. Gastroenterology 156, 748-764. doi: 10.1053/j. gastro.2018.12.009

Kole, R., Krainer, A. R., and Altman, S. (2012). RNA therapeutics: beyond RNA interference and antisense oligonucleotides. Nat. Rev. Drug Discov. 11, 125-140. doi: $10.1038 / \mathrm{nrd} 3625$

Koon, H. W., Shih, D. Q., Chen, J., Bakirtzi, K., Hing, T. C., Law, I., et al. (2011). Cathelicidin signaling via the Toll-like receptor protects against colitis in mice. Gastroenterology 141, 1852-1863.e3.

Kornbluth, A. (2015). Budesonide extended-release in patients with mild to moderate ulcerative colitis. Gastroenterol. Hepatol. 11:56.

Kriegel, C., and Amiji, M. (2011a). Oral TNF- $\alpha$ gene silencing using a polymeric microsphere-based delivery system for the treatment of inflammatory bowel disease. J. Control. Release 150, 77-86. doi: 10.1016/j.jconrel.2010.10.002

Kriegel, C., and Amiji, M. M. (2011b). Dual TNF- $\alpha /$ Cyclin D1 gene silencing with an oral polymeric microparticle system as a novel strategy for the treatment of inflammatory bowel disease. Clin. Transl. Gastroenterol. 2:e2. doi: 10.1038/ctg. 2011.1

Kumar, B., Kulanthaivel, S., Mondal, A., Mishra, S., Banerjee, B., Bhaumik, A., et al. (2017). Mesoporous silica nanoparticle based enzyme responsive system for colon specific drug delivery through guar gum capping. Coll. Surf. B Biointerfaces 150, 352-361. doi: 10.1016/j.colsurfb.2016.10.049

Lakhan, S. E., and Kirchgessner, A. (2010). Neuroinflammation in inflammatory bowel disease. J. Neuroinflamm. 7:37. doi: 10.1186/1742-2094-7-37

Lamb, C. A., Kennedy, N. A., Raine, T., Hendy, P. A., Smith, P. J., Limdi, J. K., et al. (2019). British Society of Gastroenterology consensus guidelines on the management of inflammatory bowel disease in adults. Gut 68(Suppl. 3), s1-s106.

Lamprecht, A., Schäfer, U., and Lehr, C.-M. (2001). Size-dependent bioadhesion of micro-and nanoparticulate carriers to the inflamed colonic mucosa. Pharm. Res. 18, 788-793.

Laroui, H., Dalmasso, G., Nguyen, H. T. T., Yan, Y., Sitaraman, S. V., and Merlin, D. (2010). Drug-Loaded nanoparticles targeted to the colon with polysaccharide hydrogel reduce colitis in a mouse model. Gastroenterology 138, 843-53.e2.

Laroui, H., Geem, D., Xiao, B., Viennois, E., Rakhya, P., Denning, T., et al. (2014). Targeting intestinal inflammation with CD98 siRNA/PEI-loaded nanoparticles. Mol. Ther. 22, 69-80. doi: 10.1038/mt.2013.214

Lau, J. L., and Dunn, M. K. (2018). Therapeutic peptides: historical perspectives, current development trends, and future directions. Bioorgan. Med. Chem. 26, 2700-2707. doi: 10.1016/j.bmc.2017.06.052

Lee, J. S., and Feijen, J. (2012). Polymersomes for drug delivery: design, formation and characterization. J. Control. Release 161, 473-483. doi: 10.1016/j.jconrel. 2011.10.005

Lee, J., Choi, J.-H., and Kim, H. J. (2016). Human gut-on-a-chip technology: will this revolutionize our understanding of IBD and future treatments? Expert Rev. Gastroenterol. Hepatol. 10, 883-885.

Lee, S. H., Bajracharya, R., Min, J. Y., Han, J.-W., Park, B. J., and Han, H.-K. (2020). Strategic approaches for colon targeted drug delivery: an overview of recent advancements. Pharmaceutics 12:68. doi: 10.3390/pharmaceutics12010068

Lee, Y., Sugihara, K., Gillilland, M. G., Jon, S., Kamada, N., and Moon, J. J. (2020). Hyaluronic acid-bilirubin nanomedicine for targeted modulation of dysregulated intestinal barrier, microbiome and immune responses in colitis. Nat. Mater. 19, 118-126. doi: 10.1038/s41563-019-0462-9

Leone, S., Samhan-Arias, A., Ben-Shachar, I., Derieppe, M., Dinc, F., Grosu, I., et al. (2016). ECCO-EFCCA Patient Guidelines on Ulcerative Colitis (UC). Brussels: EFCCA.

Levin, A. D., Wildenberg, M. E., and van den Brink, G. R. (2016). Mechanism of action of anti-TNF therapy in inflammatory bowel disease. J. Crohns Colitis 10, 989-997. doi: 10.1093/ecco-jcc/jjw053

Li, C., Zhao, Y., Cheng, J., Guo, J., Zhang, Q., Zhang, X., et al. (2019). A proresolving peptide nanotherapy for site-specific treatment of inflammatory bowel disease by regulating proinflammatory microenvironment and gut microbiota. Adv. Sci. 6:1900610. doi: 10.1002/advs.201900610

Li, X., Lu, C., Yang, Y., Yu, C., and Rao, Y. (2020). Site-specific targeted drug delivery systems for the treatment of inflammatory bowel disease. Biomed. Pharm. 129:110486. doi: 10.1016/j.biopha.2020.110486

Lichtenstein, G. R., Loftus, E. V., Isaacs, K. L., Regueiro, M. D., Gerson, L. B., and Sands, B. E. (2018). ACG clinical guideline: management of Crohn's disease in adults. Am. J. Gastroenterol. 113, 481-517. doi: 10.1038/ajg.2018.27

Lindsay, J., Ciesielski, C., Scheinin, T., Brennan, F., and Hodgson, H. (2003). Local delivery of adenoviral vectors encoding murine interleukin 10 induces colonic interleukin 10 production and is therapeutic for murine colitis. Gut 52, 363-369. doi: 10.1136/gut.52.3.363

Manichanh, C., Rigottier-Gois, L., Bonnaud, E., Gloux, K., Pelletier, E., Frangeul, L., et al. (2006). Reduced diversity of faecal microbiota in Crohn's disease revealed by a metagenomic approach. Gut 55, 205-211. doi: 10.1136/gut.2005.073817

Mantaj, J., and Vllasaliu, D. (2020). Recent advances in the oral delivery of biologics. Pharm. J. 15, 759-770. doi: 10.1080/17425247.2018.1504017

Mao, E., Hazlewood, G., Kaplan, G., Peyrin-Biroulet, L., and Ananthakrishnan, A. (2017). Systematic review with meta-analysis: comparative efficacy of immunosuppressants and biologics for reducing hospitalisation and surgery in Crohn's disease and ulcerative colitis. Alimentary Pharm. Ther. 45, 3-13. doi: 10.1111/apt.13847

Markham, A., and Lamb, H. M. (2000). Infliximab. Drugs 59, 1341-1359.

Matsumoto, H., Haga, K., Ohno, I., Hiraoka, K., Kimura, T., Hermann, K., et al. (2014). Mucosal gene therapy using a pseudotyped lentivirus vector encoding murine interleukin-10 (mIL-10) suppresses the development and relapse of 
experimental murine colitis. BMC Gastroenterol. 14:68. doi: 10.1186/1471230X-14-68

McKay, R., Ghodasra, M., Schardt, J., Quan, D., Pottash, A. E., Shang, W., et al. (2018). A platform of genetically engineered bacteria as vehicles for localized delivery of therapeutics: toward applications for Crohn's disease. Bioeng. Transl. Med. 3, 209-221. doi: 10.1002/btm2.10113

Misra, S., Hascall, V. C., Markwald, R. R., and Ghatak, S. (2015). Interactions between hyaluronan and its receptors (CD44, RHAMM) regulate the activities of inflammation and cancer. Front. Immunol. 6:201. doi: 10.3389/fimmu.2015. 00201

Molodecky, N. A., Soon, S., Rabi, D. M., Ghali, W. A., Ferris, M., Chernoff, G., et al. (2012). Increasing incidence and prevalence of the inflammatory bowel diseases with time, based on systematic review. Gastroenterology 142, 46-54.e42.

Monteleone, G., Kumberova, A., Croft, N. M., McKenzie, C., Steer, H. W., and MacDonald, T. T. (2001). Blocking Smad7 restores TGF- $\beta 1$ signaling in chronic inflammatory bowel disease. J. Clin. Invest. 108, 601-609. doi: 10.1172/jci12821

Monteleone, G., Neurath, M. F., Ardizzone, S., Di Sabatino, A., Fantini, M. C., Castiglione, F., et al. (2015). Mongersen, an oral SMAD7 antisense oligonucleotide, and Crohn's disease. N. Engl. J. Med. 372, 1104-1113.

Moulari, B., Béduneau, A., Pellequer, Y., and Lamprecht, A. (2014). Lectindecorated nanoparticles enhance binding to the inflamed tissue in experimental colitis. J. Control. Release 188, 9-17. doi: 10.1016/j.jconrel.2014.05.046

Murano, M., Maemura, K., Hirata, I., Toshina, K., Nishikawa, T., Hamamoto, N., et al. (2000). Therapeutic effect of intracolonically administered nuclear factor $\kappa \mathrm{B}$ (p65) antisense oligonucleotide on mouse dextran sulphate sodium (DSS)induced colitis. Clin. Exp. Immunol. 120, 51-58. doi: 10.1046/j.1365-2249.2000. 01183.x

Naeem, M., Oshi, M. A., Kim, J., Lee, J., Cao, J., Nurhasni, H., et al. (2018). pHtriggered surface charge-reversal nanoparticles alleviate experimental murine colitis via selective accumulation in inflamed colon regions. Nanomedicine 14 823-834. doi: 10.1016/j.nano.2018.01.003

Nafee, N. A., Boraie, M. A., Ismail, F. A., and Mortada, L. M. (2003). Design and characterization of mucoadhesive buccal patches containing cetylpyridinium chloride. Acta Pharm. (Zagreb, Croatia) 53, 199-212.

Namai, F., Shigemori, S., Ogita, T., Sato, T., and Shimosato, T. (2020). Microbial therapeutics for acute colitis based on genetically modified Lactococcus lactis hypersecreting IL-1Ra in mice. Exp. Mol. Med. 52, 1627-1636. doi: 10.1038/ s12276-020-00507-5

National Institute for Health and Care Excellence (2019a). Crohn's Disease: Management. London: National Institute for Health and Care Excellence

National Institute for Health and Care Excellence (2019b). Ulcerative Colitis: Management Ulcerative Colitis: Management. London: National Institute for Health and Care Excellence.

Neurath, M. F. (2014). Cytokines in inflammatory bowel disease. Nat. Rev. Immunol. 14, 329-342.

Neurath, M. F., Fuss, I., Kelsall, B. L., Stüber, E., and Strober, W. (1995). Antibodies to interleukin 12 abrogate established experimental colitis in mice. J. Exp. Med. 182, 1281-1290. doi: 10.1084/jem.182.5.1281

Nielsen, O. H., and Ainsworth, M. A. (2013). Tumor necrosis factor inhibitors for inflammatory bowel disease. N. Engl. J. Med. 369, 754-762.

Nikolaus, S., and Schreiber, S. (2007). Diagnostics of inflammatory bowel disease. Gastroenterology 133, 1670-1689. doi: 10.1053/j.gastro.2007.09.001

Nurbhai, S., Roberts, K. J., Carlton, T. M., Maggiore, L., Cubitt, M. F., Ray, K. P., et al. (2019). Oral anti-tumour necrosis factor domain antibody V565 provides high intestinal concentrations, and reduces markers of inflammation in ulcerative colitis patients. Sci. Rep. 9:14042.

Palffy, R., Gardlik, R., Behuliak, M., Jani, P., Balakova, D., Kadasi, L., et al. (2011). Salmonella-mediated gene therapy in experimental colitis in mice. Exp. Biol. Med. 236, 177-183. doi: 10.1258/ebm.2010.010277

Peyrin-Biroulet, L., Bressenot, A., and Kampman, W. (2014). Histologic remission: the ultimate therapeutic goal in ulcerative colitis? Clin. Gastroenterol. Hepatol. 12, 929-34.e2.

Poceviciute, R., and Ismagilov, R. F. (2019). Human-gut-microbiome on a chip. Nat. Biomed. Eng. 3, 500-501. doi: 10.1038/s41551-019-0425-0

Pozo, D., Delgado, M., Martı ìnez, C., Guerrero, J. M., Leceta, J., Gomariz, R. P., et al. (2000). Immunobiology of vasoactive intestinal peptide (VIP). Immunol. Today 21, 7-11. doi: 10.1016/s0167-5699(99)01525-x
Prideaux, L., Kamm, M. A., De Cruz, P. P., Chan, F. K., and Ng, S. C. (2012). Inflammatory bowel disease in Asia: a systematic review. J. Gastroenterol. Hepatol. 27, 1266-1280.

Probert, C. S., Sebastian, S., Gaya, D. R., Hamlin, P. J., Gillespie, G., Rose, A., et al. (2018). Golimumab induction and maintenance for moderate to severe ulcerative colitis: results from GO-COLITIS (Golimumab: a Phase 4, UK, open label, single arm study on its utilization and impact in ulcerative Colitis). BMJ Open Gastroenterol. 5:e00212. doi: 10.1136/bmjgast-2018-000212

Rajpurohit, H., Sharma, P., Sharma, S., and Bhandari, A. (2010). Polymers for colon targeted drug delivery. Indian J. Pharm. Sci. 72:689.

Reynolds, A., Leake, D., Boese, Q., Scaringe, S., Marshall, W. S., and Khvorova, A. (2004). Rational siRNA design for RNA interference. Nat. Biotechnol. 22, 326-330. doi: 10.1038/nbt936

Roos, N., Mahe, S., Benamouzig, R., Sick, H., Rautureau, J., and Tome, D. (1995). $15 \mathrm{~N}$-labeled immunoglobulins from bovine colostrum are partially resistant to digestion in human intestine. J. Nutr. 125, 1238-1244.

Rutgeerts, P., Vermeire, S., and Van Assche, G. (2009). Biological therapies for inflammatory bowel diseases. Gastroenterology 136, 1182-1197.

Ryder, S. D., Jacyna, M. R., Levi, A. J., Rizzi, P. M., and Rhodes, J. M. (1998). Peanut ingestion increases rectal proliferation in individuals with mucosal expression of peanut lectin receptor. Gastroenterology 114, 44-49. doi: 10.1016/s00165085(98)70631-6

Salaga, M., Binienda, A., Draczkowski, P., Kosson, P., Kordek, R., Jozwiak, K., et al. (2018). Novel peptide inhibitor of dipeptidyl peptidase IV (Tyr-Pro-D-AlaNH2) with anti-inflammatory activity in the mouse models of colitis. Peptides 108, 34-45. doi: 10.1016/j.peptides.2018.08.011

Sandborn, W. J., Feagan, B. G., Wolf, D. C., D’Haens, G., Vermeire, S., Hanauer, S. B., et al. (2016). Ozanimod induction and maintenance treatment for ulcerative colitis. N. Engl. J. Med. 374, 1754-1762. doi: 10.1056/nejmoa1513248

Sandborn, W. J., Hanauer, S. B., Katz, S., Safdi, M., Wolf, D. G., Baerg, R. D., et al. (2001). Etanercept for active Crohn's disease: a randomized, double-blind, placebo-controlled trial. Gastroenterology 121, 1088-1094.

Sandborn, W. J., Peyrin-Biroulet, L., Zhang, J., Chiorean, M., Vermeire, S., Lee, S. D., et al. (2020). Efficacy and safety of etrasimod in a phase 2 randomized trial of patients with ulcerative colitis. Gastroenterology 158, 550-561. doi: 10.1053/j.gastro.2019.10.035

Sands, B. E., Feagan, B. G., Sandborn, W. J., Schreiber, S., Peyrin-Biroulet, L., Frédéric Colombel, J., et al. (2020). Mongersen (GED-0301) for active Crohn's disease: results of a phase 3 study. Am. J. Gastroenterol. 115, 738-745. doi: 10.14309/ajg.0000000000000493

Scarozza, P., Schmitt, H., Monteleone, G., Neurath, M. F., and Atreya, R. (2019). Oligonucleotides-a novel promising therapeutic option for IBD. Front. Pharmacol. 10:314. doi: 10.3389/fphar.2019.00314

Schoellhammer, C. M., Langer, R., and Traverso, G. (2016). Of microneedles and ultrasound: physical modes of gastrointestinal macromolecule delivery. Tissue Barriers 4:e1150235. doi: 10.1080/21688370.2016.1150235

Seegers, J. F. (2002). Lactobacilli as live vaccine delivery vectors: progress and prospects. Trends Biotechnol. 20, 508-515. doi: 10.1016/s0167-7799(02)02075-9

Serra, D., Mayr, U., Boni, A., Lukonin, I., Rempfler, M., Challet Meylan, L., et al. (2019). Self-organization and symmetry breaking in intestinal organoid development. Nature 569, 66-72. doi: 10.1038/s41586-019-1146-y

Shanahan, F. (2001). Inflammatory bowel disease: immunodiagnostics, immunotherapeutics, and ecotherapeutics. Gastroenterology 120, 622-635. doi: 10.1053/gast.2001.22122

Singh, D., Srivastava, S., Pradhan, M., Kanwar, J. R., and Singh, M. R. (2015). Inflammatory bowel disease: pathogenesis, causative factors, issues, drug treatment strategies, and delivery approaches. Crit. Rev. Therap. Drug Carrier Syst. 32, 181-214. doi: 10.1615/critrevtherdrugcarriersyst.2015011095

Smith, C. I. E., and Zain, R. (2019). Therapeutic oligonucleotides: state of the art. Annu. Rev. Pharmacol. Toxicol. 59, 605-630. doi: 10.1146/annurev-pharmtox010818-021050

Song, A. A.-L., In, L. L. A., Lim, S. H. E., and Rahim, R. A. (2017). A review on Lactococcus lactis: from food to factory. Microb. Cell Factor. 16:55.

Steidler, L., and Rottiers, P. (2006). Therapeutic drug delivery by genetically modified Lactococcus lactis. Ann. N. Y. Acad. Sci. 1072, 176-186. doi: 10.1196/ annals. 1326.031 
Steidler, L., Hans, W., Schotte, L., Neirynck, S., Obermeier, F., Falk, W., et al. (2000). Treatment of murine colitis by Lactococcus lactis secreting interleukin-10. Science 289, 1352-1355. doi: 10.1126/science.289.5483.1352

Steidler, L., Neirynck, S., Huyghebaert, N., Snoeck, V., Vermeire, A., Goddeeris, B., et al. (2003). Biological containment of genetically modified Lactococcus lactis for intestinal delivery of human interleukin 10. Nat. Biotechnol. 21, 785-789. doi: $10.1038 /$ nbt840

Strober, W., Fuss, I., and Mannon, P. (2007). The fundamental basis of inflammatory bowel disease. J. Clin. Invest. 117, 514-521. doi: 10.1172/jci30587

Su, C. G., Wen, X., Bailey, S. T., Jiang, W., Rangwala, S. M., Keilbaugh, S. A., et al. (1999). A novel therapy for colitis utilizing PPAR- $\gamma$ ligands to inhibit the epithelial inflammatory response. J. Clin. Invest. 104, 383-389. doi: 10.1172/ jci7145

Suk, J. S., Xu, Q., Kim, N., Hanes, J., and Ensign, L. M. (2016). PEGylation as a strategy for improving nanoparticle-based drug and gene delivery. Adv. Drug Deliv. Rev. 99, 28-51. doi: 10.1016/j.addr.2015.09.012

Sun, Q., Luan, L., Arif, M., Li, J., Dong, Q.-J., Gao, Y., et al. (2018). Redox-sensitive nanoparticles based on 4-aminothiophenol-carboxymethyl inulin conjugate for budesonide delivery in inflammatory bowel diseases. Carbohydrate Polym. 189, 352-359. doi: 10.1016/j.carbpol.2017.12.021

Takahashi, Y., Nishikawa, M., and Takakura, Y. (2009). Nonviral vector-mediated RNA interference: its gene silencing characteristics and important factors to achieve RNAi-based gene therapy. Adv. Drug Deliv. Rev. 61, 760-766. doi: 10.1016/j.addr.2009.04.006

Thompson, A. I., and Lees, C. W. (2010). Genetics of ulcerative colitis. Inflamm. Bowel Dis. 17, 831-848.

Torres, J., Bonovas, S., Doherty, G., Kucharzik, T., Gisbert, J. P., Raine, T., et al. (2020). ECCO guidelines on therapeutics in Crohn's disease: medical treatment. J. Crohns Colitis. 14, 4-22.

Torres, J., Bonovas, S., Doherty, G., Kucharzik, T., Gisbert, J. P., Raine, T., et al. (2019). ECCO guidelines on therapeutics in Crohn's disease: medical treatment. J. Crohns Colitis. 14, 4-22.

Traverso, G., Schoellhammer, C. M., Schroeder, A., Maa, R., Lauwers, G. Y., Polat, B. E., et al. (2015). Microneedles for drug delivery via the gastrointestinal tract. J. Pharm. Sci. 104, 362-367.

Tseng, Y.-C., Mozumdar, S., and Huang, L. (2009). Lipid-based systemic delivery of siRNA. Adv. Drug Deliv. Rev. 61, 721-731. doi: 10.1016/j.addr.2009.03.003

Vandenbroucke, K., de Haard, H., Beirnaert, E., Dreier, T., Lauwereys, M., Huyck, L., et al. (2010). Orally administered L. lactis secreting an anti-TNF Nanobody demonstrate efficacy in chronic colitis. Mucosal Immunol. 3, 49-56. doi: 10. 1038/mi.2009.116

Viennois, E., Ingersoll, S. A., Ayyadurai, S., Zhao, Y., Wang, L., Zhang, M., et al. (2016). Critical role of PepT1 in promoting colitis-associated cancer and therapeutic benefits of the anti-inflammatory PepT1-Mediated tripeptide KPV in a murine model. Cell. Mol. Gastroenterol. Hepatol. 2, 340-357. doi: 10.1016/j.jcmgh.2016.01.006

Voinnet, O. (2005). Induction and suppression of RNA silencing: insights from viral infections. Nat. Rev. Genet. 6, 206-220. doi: 10.1038/nrg1555

Vong, L. B., Tomita, T., Yoshitomi, T., Matsui, H., and Nagasaki, Y. (2012). An orally administered redox nanoparticle that accumulates in the colonic mucosa and reduces colitis in mice. Gastroenterology 143, 1027-1736.e3.

Vos, A. C. W., Wildenberg, M. E., Arijs, I., Duijvestein, M., Verhaar, A. P., De Hertogh, G., et al. (2012). Regulatory macrophages induced by infliximab are involved in healing in vivo and in vitro. Inflamm. Bowel Dis. 18, 401-408. doi: 10.1002/ibd.21818

Vos, A. C. W., Wildenberg, M. E., Duijvestein, M., Verhaar, A. P., van den Brink, G. R., and Hommes, D. W. (2011). Anti-tumor necrosis factor- $\alpha$ antibodies induce regulatory macrophages in an $\mathrm{Fc}$ region-dependent manner. Gastroenterology 140, 221-230.e3.

Wang, J., Lu, Z., Wientjes, M. G., and Au, J. L. S. (2010). Delivery of siRNA therapeutics: barriers and carriers. AAPS J. 12, 492-503. doi: 10.1208/s12248010-9210-4

Wang, X., Yamamoto, Y., Wilson, L. H., Zhang, T., Howitt, B. E., Farrow, M. A., et al. (2015). Cloning and variation of ground state intestinal stem cells. Nature $522,173-178$.

Wang, X., Yan, J., Wang, L., Pan, D., Xu, Y., Wang, F., et al. (2020). Oral delivery of anti-TNF antibody shielded by natural polyphenol-mediated supramolecular assembly for inflammatory bowel disease therapy. Theranostics 10, 1080810822. doi: $10.7150 /$ thno. 47601
Wilson, D. S., Dalmasso, G., Wang, L., Sitaraman, S. V., Merlin, D., and Murthy, N. (2010). Orally delivered thioketal nanoparticles loaded with TNF- $\alpha$-siRNA target inflammation and inhibit gene expression in the intestines. Nat. Mater. 9, 923-928. doi: 10.1038/nmat2859

Wirth, T., Parker, N., and Ylä-Herttuala, S. (2013). History of gene therapy. Gene 525, 162-169. doi: 10.1016/j.gene.2013.03.137

Wirtz, S., and Neurath, M. F. (2007). Mouse models of inflammatory bowel disease. Adv. Drug Deliv. Rev. 59, 1073-1083.

Wu, Y., Sun, M., Wang, D., Li, G., Huang, J., Tan, S., et al. (2019). A PepT1 mediated medicinal nano-system for targeted delivery of cyclosporine A to alleviate acute severe ulcerative colitis. Biomat. Sci. 7, 4299-4309. doi: 10.1039/c9bm00925f

Xiao, B., Xu, Z., Viennois, E., Zhang, Y., Zhang, Z., Zhang, M., et al. (2017). Orally targeted delivery of tripeptide KPV via hyaluronic acid-functionalized nanoparticles efficiently alleviates ulcerative colitis. Mol. Ther. 25, 1628-1640. doi: 10.1016/j.ymthe.2016.11.020

Yang, C., and Merlin, D. (2019). Nanoparticle-mediated drug delivery systems for the treatment of IBD: current perspectives. Int. J. Nanomed. 14:8875. doi: $10.2147 /$ ijn.s210315

Yang, C., and Merlin, D. (2020). Can naturally occurring nanoparticle-based targeted drug delivery effectively treat inflammatory bowel disease? Expert Opin. Drug Deliv. 17, 1-4. doi: 10.1080/17425247.2020.1698543

Yang, M., Zhang, Y., Ma, Y., Yan, X., Gong, L., Zhang, M., et al. (2020). Nanoparticle-based therapeutics of inflammatory bowel diseases: a narrative review of the current state and prospects. J. Bio-X Res. 3, 157-173. doi: 10.1097/ jbr.0000000000000078

Yun, Y., Cho, Y. W., and Park, K. (2013). Nanoparticles for oral delivery: targeted nanoparticles with peptidic ligands for oral protein delivery. Adv. Drug Deliv. Rev. 65, 822-832. doi: 10.1016/j.addr.2012.10.007

Zhang, J., Tang, C., and Yin, C. (2013). Galactosylated trimethyl chitosan-cysteine nanoparticles loaded with Map4k4 siRNA for targeting activated macrophages. Biomaterials 34, 3667-3677. doi: 10.1016/j.biomaterials.2013.01.079

Zhang, L., Zhu, W., Yang, C., Guo, H., Yu, A., Ji, J., et al. (2012). A novel folatemodified self-microemulsifying drug delivery system of curcumin for colon targeting. Int. J. Nanomed. 7:151. doi: 10.2147/ijn.s27639

Zhang, M., Viennois, E., Prasad, M., Zhang, Y., Wang, L., Zhang, Z., et al. (2016). Edible ginger-derived nanoparticles: a novel therapeutic approach for the prevention and treatment of inflammatory bowel disease and colitis-associated cancer. Biomaterials 101, 321-340. doi: 10.1016/j.biomaterials.2016.06.018

Zhang, M., Wang, X., Han, M. K., Collins, J. F., and Merlin, D. (2017). Oral administration of ginger-derived nanolipids loaded with siRNA as a novel approach for efficient siRNA drug delivery to treat ulcerative colitis. Nanomedicine (Lond) 12, 1927-1943. doi: 10.2217/nnm-2017-0196

Zhang, W., Böttger, R., Qin, Z., Kulkarni, J. A., Vogler, J., Cullis, P. R., et al. (2019). Phospholipid-Free small unilamellar vesicles for drug targeting to cells in the liver. Small 15:1901782. doi: 10.1002/smll.201901782

Zhang, Y.-Z., and Li, Y.-Y. (2014). Inflammatory bowel disease: pathogenesis. World J. Gastroenterol. 20, 91-99.

Zhou, H., and Qian, H. (2018). Preparation and characterization of pH-sensitive nanoparticles of budesonide for the treatment of ulcerative colitis. Drug Des. Dev. Ther. 12:2601. doi: 10.2147/dddt.s170676

Zu, M., Song, H., Zhang, J., Chen, Q., Deng, S., Canup, B. S., et al. (2020). Lycium barbarum lipid-based edible nanoparticles protect against experimental colitis. Coll. Surf. B Biointerfaces 187:110747. doi: 10.1016/j.colsurfb.2019. 110747

Zundler, S., Becker, E., Weidinger, C., and Siegmund, B. (2017). Anti-adhesion therapies in inflammatory bowel disease-molecular and clinical aspects. Front. Immunol. 8:891. doi: 10.3389/fimmu.2017.00891

Conflict of Interest: The authors declare that the research was conducted in the absence of any commercial or financial relationships that could be construed as a potential conflict of interest.

Copyright (c) 2021 Zhang, Michalowski and Beloqui. This is an open-access article distributed under the terms of the Creative Commons Attribution License (CC BY). The use, distribution or reproduction in other forums is permitted, provided the original author(s) and the copyright owner(s) are credited and that the original publication in this journal is cited, in accordance with accepted academic practice. No use, distribution or reproduction is permitted which does not comply with these terms. 